ISSN: 0514-7336 — ISSN electrónico: 2386-3943

DOI: https://doi.org/10.14201/zephyrus202187167193

\title{
LA VOZ A TRAVÉS DEL CUERNO. EL PARADIGMA DOCUMENTAL DEL CARNYX
}

\section{The Voice through the Horn. The Documentary Paradigm of Carnyx}

\author{
Gabriel Sopeña Genzor \\ Dpto. de Ciencias de la Antigüedad. Facultad de Filosofía y Letras. Univ. de Zaragoza. Edificio Cervantes. Cl \\ Corona de Aragón, 42. 50009 Zaragoza. Correo-e: gsopena@unizar.es. ID ORCID: https:/lorcid.org/0000-0002- \\ $8971-5656$
}

Recepción: 25/08/2020; Revisión: 10/02/2020; Aceptación: 5/04/2021

Resumen: Tanto las fuentes literarias griegas y latinas como la iconografía céltica demuestran la gran relevancia del carnyx -como paradigma de la feritas, en la visión general de helenos y romanos-y como exponente del decorum, para los propios nativos. De esta manera, el ancestral cuerno de guerra en bronce de los celtas -al que debe sumarse la peculiaridad de las trompetas celtibéricas en arcilla- exhibe una relevancia arqueológica y simbólica definitoria, relacionada con el espíritu y el ethos de estas gentes de la Europa protohistórica. Los descubrimientos del s. Xxi permiten la reconstrucción de algunos prototipos que muestran un cierto potencial musical, únicamente en nuestros términos contemporáneos por supuesto, además de su destacada y primigenia finalidad militar, de advertencia e intimidación. La decoración zoomorfa de sus altavoces caracteriza estas piezas como únicas en la Historia de la Organología: un rasgo definitorio relacionado con su función como traductoras de una sacra dictio en el panorama sacrificial de la esfera bélica celta.

Palabras clave: Edad del Hierro; Arqueología Céltica; Arqueología Musical; trompetas bélicas; ética y religión céltica; alteridad.

АвSтRACT: Both Greek and Latin literary sources also as Celtic iconography show the great relevance of the carnyx -as a paradigm of the feritas, in the general view of Hellenes and Romans- and as an exponent of the decorum, for the natives themselves. This way, the ancestral Celtic bronze war horn -as well with the peculiarity of the Celtiberian trumpets in clay- exhibits a defining archaeological and symbolic relevance connected to the ideology and the ethos of these people of protohistoric Europe. The discoveries of the 21 st century allow the reconstruction of some prototypes that show a certain musical potential, of course only in our contemporary terms, beside their prominent and primal military purpose, of warning and intimidation. The zoomorphic decoration of their speakers characterizes these unique pieces in the History of Organology: a defining trait related to their function as translators of a sacra dictio in the sacrificial panorama of the Celtic war sphere.

Key words: Iron Age; Celtic Archaeology; Musical Archaeology; War Trumpets; Celtic ethos and religion; Otherness. 


\section{El cuerno y el carnyx Cuestiones onomásticas}

Desde época hallstáttica y hasta la Era cristiana, el mundo céltico conoció aerófonos metálicos, óseos y en madera. Pero el ancestral carnyx descolla por su relevancia arqueológica y simbólica, definitoria del ethos de estas gentes, según sus propias expresiones materiales y en la visión que de estos bárbaros de la Europa templada transmitieron griegos y latinos (Sopeña, 2012; Eibner, 2013; Hunter, 2019).

El nombre del instrumento ha sido legado por gramáticos tardíos; y Hesiquio asimila la palabra gálata referida a la trompeta bélica a la salpin $x$ grie-

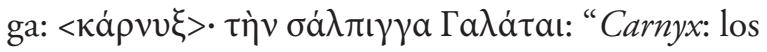
gálatas llaman así a la salpinge" (Hesiquio, Kappa 841). Por su parte Eustacio -1110-1198 d. C.-, basándose en obras antiguas (Georgiadou, 1998), describía seis variedades de salpinges:

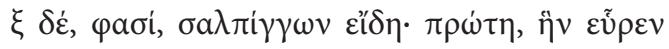

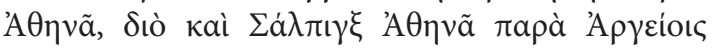

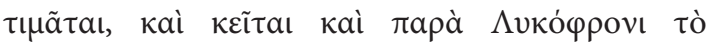

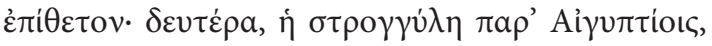

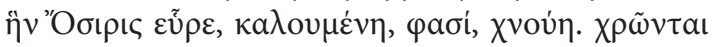

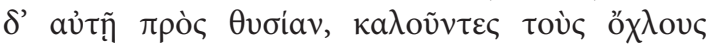

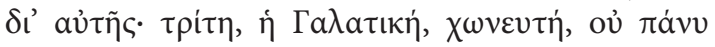

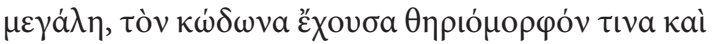

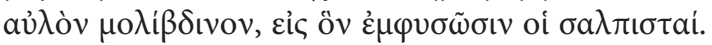

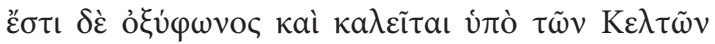

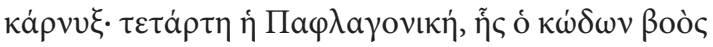

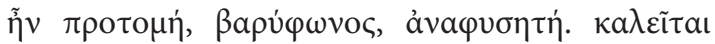

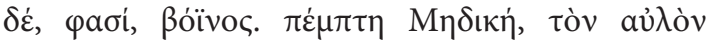

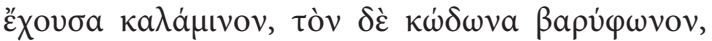

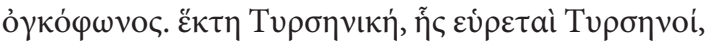

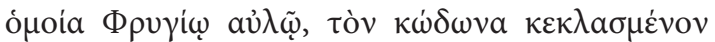

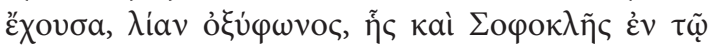

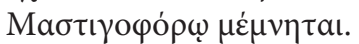

Además, dicen que son seis los tipos de salpinges: la primera, la que inventó Atenea, razón por la cual se honra a Atenea entre los argivos como Atenea

1 El autor es miembro del Grupo de Investigación HIBerus y del Instituto Universitario de Patrimonio y Humanidades. Nuestra sincera gratitud a los profesores V. Ramón Palerm, M. Á. Rodríguez Horrillo (Univ. de Zaragoza), A. Santos Cancelas, C. García Benito; y a P. Lanzarote, por la confección del aparato gráfico.
Salpinge, epíteto que se aplica incluso a Licofrón; la segunda, la redondeada de los egipicios, que inventó Osiris y que, según dicen, se denomina Cnúe. La usan en los sacrificios, a fin de convocar con ella a las multitudes. La tercera, la gálata, de metal fundido, no excesivamente grande, que tiene un pabellón como con forma de animal, y una boquilla de plomo, por la que soplan los salpistas; es de sonido agudo y los celtas la denominan carnyx. La cuarta, la paflagonia, cuyo pabellón tiene forma de cabeza de toro, es de sonido grave, y se sopla desde abajo. Se llama, dicen, boinos. La quinta es la meda, cuya boquilla es de caña, y su pabellón de sonido grave, ahogado. La sexta la tirrena, cuya invención corresponde a los tirrenos, es semejante a la frigia, con un pabellón rico en sonidos de lamento, excesivamente aguda, de la que incluso Sófocles hace mención en el Mastigóforo.

(Eustacio, Comentarios a Homero, 18. 219. Traducción: Rodríguez Horrillo)

En cuanto a la gálata, los escolios de donde procede la obra eustaciana matizan que la boquilla de plomo está sujeta en el interior: "'̌́ $\sigma \omega \theta \varepsilon v \delta \varepsilon$

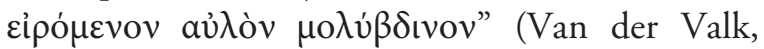
1987: ad locum). En fin, una salpinge de Pafaglonia, de tono grave y altavoz simulando un prótomo de

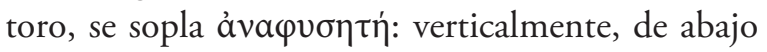
arriba. El verbo griego relacionado con este adjetivo se aplica a volcanes en erupción, conque la imagen del hápax resulta pragmática (Erbse, 1975).

\section{Cuernos animales, cuernos divinos}

Ká $\rho v v \xi$ deriva del radical indoeuropeo alusivo al cuerno: ${ }^{*} \operatorname{ker}(\mathrm{n})$, de donde cornū, кápvoৎ o cern. Hay etnónimos derivados: los carnutos de Cenabum, los Carni alpinos o los Carnonacae de Sutherland (Delamarre, 2003: s. v.; Villar y Prósper, 2005: 82-85) y en cuanto a teónimos destaca Cernunnos, de plurifuncionalidad benéfica y salvaje expresada mediante su cornamenta. Citado en el Pilar de los Nautas dedicado a Tiberio, fue definido iconográficamente con el torques y como pacífico $\delta \varepsilon \sigma \pi$ tó $\rceil \varsigma$ $\theta \eta \rho \tilde{\omega} v$ (Gricourt y Hollard, 2010). Destaca su sociedad con la serpiente criófora, con unas treinta 
representaciones: desde el ara de Lypiatt Park hasta el vaso de Arcóbriga, pasando por los ejemplos de los nervii del Escalda (Green, 1992: 229; Marco, 2003; Amand, 1970).

Animal compuesto por el cuerpo de la culebra y la testa armada del carnero, engloba la potencialidad de la regeneración encarnada en el ofidio y el desbordante vigor viril que atesora el cabro. Por ello este monstruo se halla en intimidad con el también astado Cernunnos -aunque acompaña a Marte en el altar de Mavilly; o a Mercurio, en la estatuilla de Yzeuvres-sur-Creuse y el vaso de Sains du Nord-, hasta el punto de que en el relieve de Cirencester las piernas del dios son sendas sierpes crióforas, ascendiendo para pacer los granos surgidos de la cabeza de este (Green, 1992: 194; 2004: 153-160).

Cornutus, epíteto latino de Cordonus en un epígrafe de Peñalba de Villastar, muestra la interpretatio de una divinidad indígena adscribible a las céltico-romanas con cuernos (Beltrán et al., 2005: 932 y ss.; De Bernardo, 2008: 191-192; Marco y Sopeña, 2017: 137). Aparte de su relación con Cernunnos, constan los bóvidos galos tricornes -como el de Auxy, dedicado a Lugus (Deyts, 1992: 3033) - y otros en Britania: Cookham, Cirencester o Colchester (Green, 1992: 221 y 223). Esta personalidad de atávica pujanza, proclamada mediante su astado tríplice, será asimilada al Mars Vltor augusteo, según corrobora un Marte broncíneo de tres cuernos - con un toro en su torso- conservado en Madrid (Marco, 2006).

Por su espesor simbólico, los cuernos intensifican la potencia divina (Ross, 1967: 302-308) y el uso epigráfico sanciona ese tipo. De tal suerte, el Karnonos de Montagnac (RIG I, G 224) y también la inscripción narbonense de Montjustin -Apta Iulia-, ofrecida a Iovi Corn[uto] o Corn[iger] ( $A E$, 1990: 711), excelente sincretismo entre una divinidad gálica y el jerarca del panteón romano, paralelo del Cornutus Cordonus (Beltrán et al., 2005: 938-939), la figura jánica de Peñalba presenta cuernos y, según estas evidencias, aceptando una datación antigua podría tratarse del Cordono citado en el 'Gran Panel' (Marco, 1997).

La capacidad de ataque, el vigor y la fertilidad encarnadas en los cuernos animales explican la iconografía de dioses cornudos en la Céltica, desde el 'Jano' de Holzgerlingen del s. Iv a. C. (Deyts, 1992: 30-46; Green, 1992: 230-238). Así, en Hispania los relieves de Lourizán y de Candelario; en la Galia con muestras en Blain (Nantes) o Beire-le-Chapel; y en Britania destacando, entre los brigantes, el Mercurio de West Uley (Green, 2004: 221-222). En definitiva, el cuerno convierte en boyante a la deidad -siue deus, siue dea, demostrándolo una diosa gala con astas (Green, 2004: 79)-, y resulta elocuente aplicado a seres $\mathrm{u}$ objetos profanos que carecen naturalmente de él. De ahí los muchos cascos célticos cornudos (Diodoro, 5. 30), con exponentes eximios: el del puente de Waterloo, uno triastado de Cork (Raftery, 1991: 568) o los de Aranda o Mosqueruela (Lorrio y Royo, 2013; Graells et al., 2014). De ahí asimismo la simbología de los hombres tricornes de Haferturm, Walsingham (Green, 2004: 209-211), Moñes (Marco, 1998) o Numancia (Sopeña, 1995: 231-232, fig. 58); la voluntad de convertir a un caballo en cornúpeta con la testera de Torrs, una máscara metálica, con profusa decoración ornitoforma y dos cuernos rematados a su vez con aves (Briggs, 2014); o el jabalí de Cahors dotado de genitales de macho y mamas -en la indefinición primordial de lo divino (Raepsaet-Charlier, 1993; Marco, 2002)- que añade tres puntas en su testuz, desvelando su sacralidad (Green, 2004: 83).

El valor del cuerno se postula enseña protectora, heroificadora y consigna de poder en la Céltica; y con tal calidad adorna objetos en tumbas y depósitos. Toros constan en los calderos, materiales oblativos por antonomasia dada su potencialidad transformadora (Sopeña, 1995: 36-37 y 151-152), con los ejemplos dinamarqueses de Brå y Gundestrup; también en morillos en ámbito sepulcral, como en Mayllerare-sur-Seine, del s. II a. C. (Maier, 1991: 419). Destacan el ajuar de tazas cornudas de la necrópolis eslovaca de Bučany, del s. v a. C. (Biel, 1991: 137); los vasos de Csobaj (Hungría), del s. III a. C., con asas como testas de carnero (Szabó, 1991: 317), o, en fin, la sortija ornada de toros y aves acuáticas del tesoro votivo que un tal Korisios -en inscripción en griego, sobre una espada- arrojó al río, similar al anillo del oppidum de Stradonice, 
atiborrado de cuernos (Bren, 1991; Rybová y Drda, 1994: 117-121).

Siendo la cerveza bebida ordinaria (Nelson, 2008), el vino mediterráneo fue apreciado apasionadamente por estas gentes (Marco, 2009; Poux, 2009). El uso de cuernos suntuosos para consumir licor revela la importancia antropológica de este (César, Guerra de las Galias, 6. 28; Plinio, Historia Natural, 11. 45. 126). El de Hochdorf -c. 530 a. C.- se hizo en hierro repujado con hilo áurico y con un remate de ornatos óseos (Krauße, 1996; Hansen, 2010); los dos ejemplares de oro de Kleinaspergle, con resabios pónticos, acabados con cabeza de cabro (Fischer, 1991: 178; Kimming, 1998); o el cuerno magiar de Jászberény-Cserohälum -s. II a. C.-, de inspiración tracia, en forma de endriago con fauces abiertas (Frey y Szabó, 1991: 483). Adornar los cuernos libatorios con monstruos perduró -apréciese la estela picta de Bullion, del s. Ix d. C. (Laing y Laing, 1984)-, intentando incrementar la intensidad simbólica del asta sumándole una figura sobrenatural o la cabeza de un animal de brío icónico: tal y como Eustacio indicaba para el carnyx.

\section{Instrumentos poderosos. La interpretatio grecolatina}

Un carnyx es un cuerno por su origen prehistórico, cuando la humanidad utilizó este como aerófono (Coles, 1963; Clodoré-Tissot et al., 2009), y lo es por su función y ostentoso simbolismo animalesco. Como tal conservó su nombre, su forma readaptada y su significación vinculada al ethos agonístico (Eibner, 2013).

Nuestras fuentes inscriben unánimemente al instrumento en panoramas bélicos. Polibio, Diodoro y Apiano lo asimilan a la $\Sigma \alpha \lambda \pi \iota \gamma$ griega, siendo

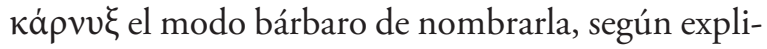
carán siglos después Hesiquio y Eustacio:

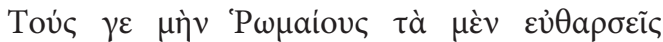

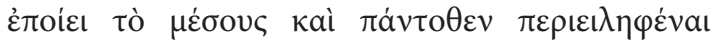

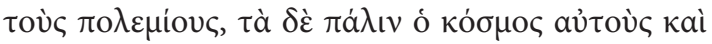

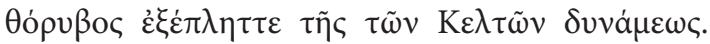

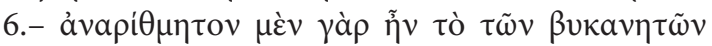

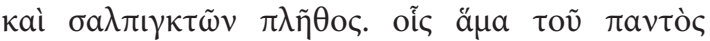

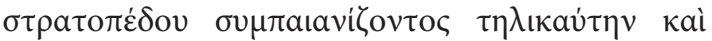

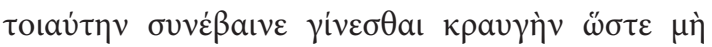

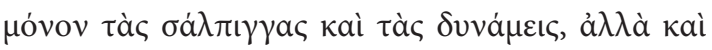

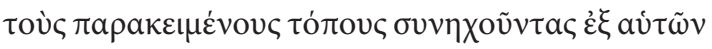

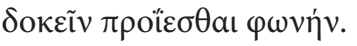

Por cuanto concierne a los romanos, les animaba el hecho de que los enemigos se hallaran en el centro y rodeados por doquier. Sin embargo, el orden y el clamor de los efectivos celtas los sobrecogían. El caso es que la cuantía de bocineros y de salpinges era innumerable. Junto a estos factores y con todo el ejército entonando un peán al unísono, sucedía que se produjo un estruendo tamaño y de condición tal que no solo las salpinges y los efectivos militares sino que también los lugares aledańos parecían proyectar un sonido propio.

(Polibio 2. 29. 5-6. Traducción: Ramón Palerm)

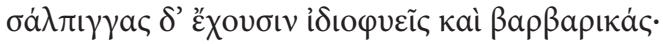

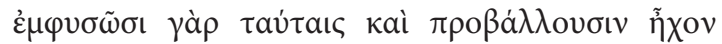

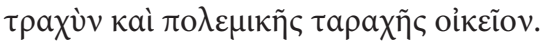

[Los celtas] tienen unas salpinges de naturaleza particular y bárbara: pues las tocan y emiten un sonido desagradable y adecuado al desorden del combate.

(Diodoro 5. 30. 3. Traducción: Rodríguez Horrillo)

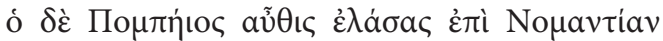

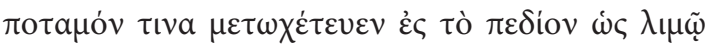

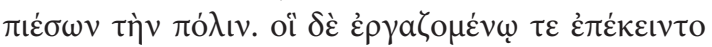

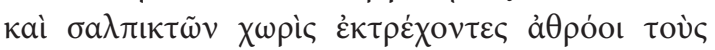

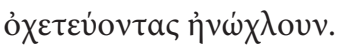

[Quinto] Pompeyo [Aulo], una vez reanudado el ataque contra Numancia desvió el curso de un río hacia la llanura, con el propósito de someter por hambre a la ciudad. Pero ellos [los numantinos] le atacaron mientras se dedicaba a esta tarea, y sin señal alguna de salpinges, saliendo todos juntos a la carrera, hostigaron a los que trabajaban en el río.

(Apiano, Ibérica, 78. 332. Traducción: Rodríguez Horrillo) 
Atilio Régulo y Emilio Papo abortaron la invasión cisalpina del 225 en Telamón (Champion, 2000: 429-432; Erdkamp, 2009). Aunque condenada ante el $\lambda$ ó $\iota \sigma \mu o \varsigma$ romano, Polibio considera formidable la brega céltica; y escoge escrupulosa-

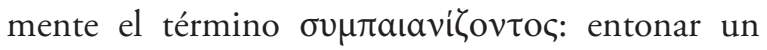
peán al unísono entre la batahola de las salpinges parangona los cantos bárbaros con el Пaı́áv apolíneo, que habilitó un género literario helénico (Schröder, 1999). La definición de este espacio consagrado, mediante el alboroto de carnyces, bukaneto $i$ y cánticos, sustenta la interpretatio racionalista polibiana. Un siglo después, Diodoro -también devoto estoico- revela que el sonido de estas salpinges es 'desagradable' a oídos griegos; pero su 'naturaleza' peculiar es 'adecuada' -términos troncales para el Pórtico (Sopeña y Ramón, 2002)- en el 'desorden' del combate celta. En fin, Apiano relata uno de los fracasos ante Numancia de Pompeyo Aulo, un inepto contumaz, gobernador de la Citerior en 141: los arévacos no usaron salpinges como habitualmente, pues procuraron el sigilo (Sopeña, 1995: 105).

El matiz estridor de la palabra $\Sigma \alpha \lambda \pi \imath \gamma$ es privativo en griego: remite al enardecimiento y su destino específico fue bélico (Krentz, 1993; Petretto, 1995; Xanthoulis, 2006; Nooter, 2019). Sucede que desde 396 a. C. los salpistas compitieron en los Juegos Olímpicos, delatando la exigencia de la disciplina y su tenor religioso, hechos traducidos por Polibio para los celtas: en estos certámenes se venció por la potencia soplando. Ínclito exponente es Heródoro de Mégara, héroe en Argos con Demetrio Poliorcetes. Con su $\Sigma \alpha \lambda \pi \imath \gamma$ obtuvo al menos diez coronas entre 328-292 a. C. Glotón y borrachín, soplaba dos instrumentos simultáneamente, atronando. La animalidad de su ejercicio la refrendaba su atavío con un pellejo de león y su pernocta sobre otro de oso (Ateneo, Banquete 10. 414e-415a; Julio Pólux, Onomástico 4. 89. West, 1994: 118).

Excepcionalmente el término hierosalpinktés alude a la Atenea argiva: su talante estridor es discreto, como patrona protectora; y exige la contención de los salpistas, frente a la plétora dionisiaca del aulós (Serghidou, 2001; Hale, 2003; Bundrick, 2005: 42-45). Como los cornua, bucinae y tubae romanos

Ediciones Universidad de Salamanca / @®ఠ
- limitados a la guerra, la pompa o las uenationes (Fleischhauer, 1964: 64, 68; Donaldson, 1988; Landels, 2000: 78-79 y 177-180; Mazzino, 2008; Vincent, 2020)-, su objetivo fue el aviso (West, 1994: 118-121).

\section{Cuernos bramantes: el instrumento}

Por su aspecto y su sonoridad, el carnyx estaba concebido originariamente para intimidar alborotando. Elaborado en chapa de bronce, se compone de un tubo troncocónico vertical en cuyo extremo inferior se ubica la boquilla; y de un altavoz en el extremo superior que, perpendicular a la tubería, simula la testa de un animal de fauces abiertas, confiriéndole su carácter distintivamente céltico, acreditando a Eustacio y a la iconografía de Gundestrup (Hachmann, 1990; Kaul y Martens, 1995). Hasta fechas recientes solo eran conocidos fragmentos, oriundos de depósitos ceremoniales. Una de las 150 piezas del conjunto vótivo de Llyn Cerrig Bach (Anglesey) pudo pertenecer a un carnyx (MacDonald, 2007: 107), como quizá cuatro ejemplares perdidos -encontrados junto a la célebre trompeta- en el Lago de Loughnashade, asociados con cráneos humanos y en dádiva a las aguas (Raftery, 2001: 68; O’Dwyer et al., 2002); verosímilmente también el fragmento transilvano de Săliștea y el de la colección Severeanu de Bucarest (Hunter, 2019: 190-194 y 195); pero deben desestimarse el bronce ornitomorfo de Castiglione delle Stivere -incapaz acústicamente- y el artefacto de Malberg (Fig. 1) (Vendries, 1999: 370-373; cf. Bochnack y Frankowsky, 2010).

En 1768, en Tattershall Ferry, fue hallado un ejemplar sin la bocina; y en 1816, exhumado de una turbera en Deskford, un altavoz, figurando una cabeza de jabalí, del s. i a. C. y carente de tubería. Las fauces contenían una lengua lígnea montada sobre un eje que vibraba con determinadas frecuencias (Fig. 2), permitiendo así sonidos poderosos (Piggott, 1959: 24-29; Hunter, 2019: 11-122). La restauración se basó en los salpistas de Gundestrup: no había sido hallada embocadura alguna hasta 
entonces. John Kenny estrenó el carnyx en Smoo Cave -escondrijo vikingo en Caledonia- en 1993. Desde entonces el maestro (Fig. 3), mediante sofisticadas destrezas actuales -respiración circular, ayuda gutural, bendings-, demuestra incluso orquestalmente las contemporáneas posibilidades musicales de aquel, que jamás deben extrapolarse, evidentemente, a su antiguo uso genuino (Gilbert et al., 2012; Hunter, 2019: 317-319).

La segunda bocina de carnyx, datable en el cambio de Era, procede de un santuario indígena reconsagrado a Marte y Belona en Epomanduodunum,
Mandeure. El pabellón representa un jabalí con la boca abierta, defensas explícitas y pelambrera crespa. El instrumento fue reconstruido en 1996 por el Museo de Bibracte (Fig. 4) (Campbell y MacGillivray, 1998 y 2000; Creed, 2000; Hunter, 2000; Kenny, 2000; Barral et al., 2007: 384-388).

En 2004 fue hallado en Tintignac un depósito votivo del siglo III a. C. con varios carnyces broncíneos, cinco con pabellón de cabeza de jabalí y uno de serpiente dentada (Fig. 5). La tubería dispuso de emboque recto y todos exhibían plaquitas simulando orejas -de $40 \mathrm{~cm}$ las mayores-, comunicadas con

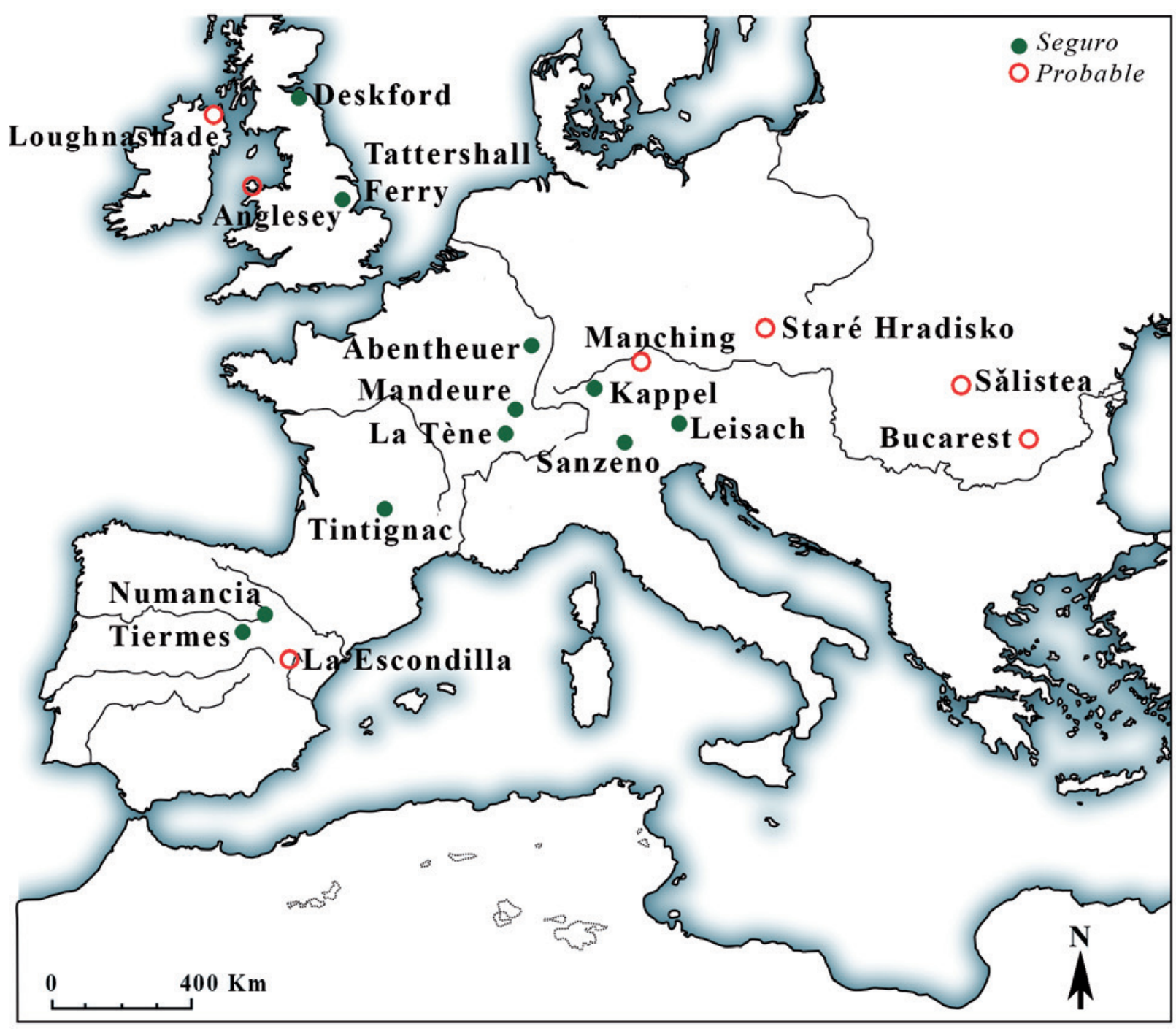

FIG. 1. Distribución geográfica de los hallazgos arqueológicos de carnyces y trompetas celtibéricas. 
el tubo para acompasar el soplido. A la luz de este descubrimiento, de los de Sanzeno (Roncador, 2014) y Leisach (Gleischer, 2014), y atendiendo a los adminículos móviles de Desfork, se admite que los ejemplos de Abentheuer, Kappel, La Tène y Mandeure tuvieron láminas fijadas a la bocina para incremento acústico (Fig. 6). Los excavadores del enclave reconocen todos los elementos de los carnyces de Gundestrup, sugiriendo que el conjunto de Tintignac obedeció a rituales parangonables al de la joya danesa (Maniquet, 2008; Maniquet et al., 2009, 2011; Deyber, 2009: 127, 288) (Fig. 7). Estos hallazgos demuestran que los carnyces midieron circa 1,80 m; como aseguraba Eustacio,

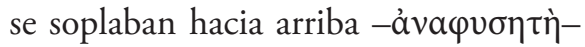
sobre una boquilla recta (Fig. 8); y el pabellón podía sobresalir 3 metros del suelo (Homo-Lechner y Vendries, 1993; Vendries, 1999: 383-388; Campbell y MacGillivray, 1998 y 2000; Creed, 2000; Kenny, 2000; O’Dwyer, Kenny y Creed, 2002; Hunter, 2019), una verdadera 'arma psicológica' (Gleirscher, 2014: 111) estremeciendo acústicamente y visualmente (Fig. 9).

\section{La peculiaridad celtibérica}

El carnyx es un cuerno incomparable por su exclusivo ornato zoomorfo
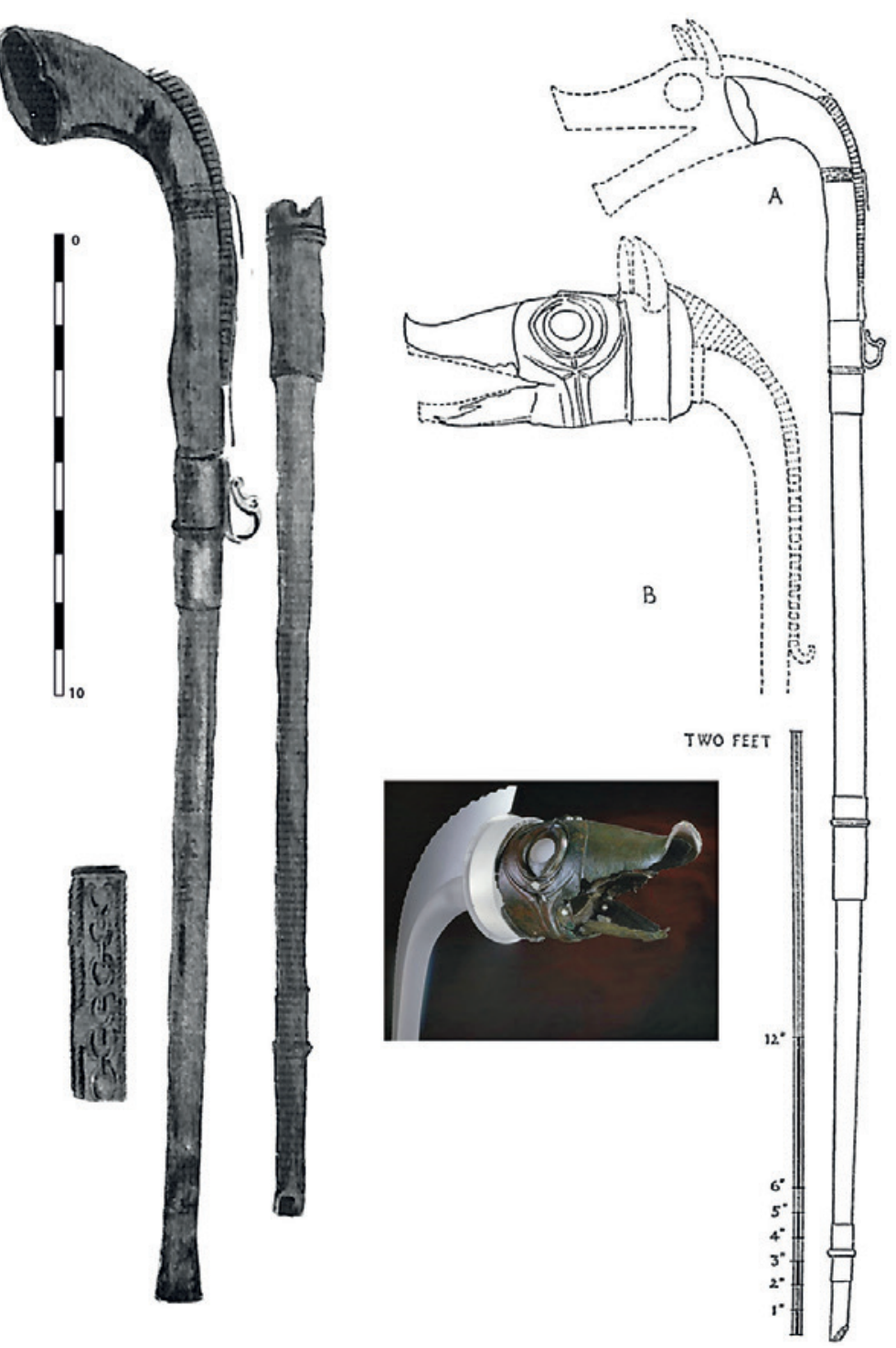

FIG. 2. Carnyces de Deskford-National Museum of Scotland-y Tattershall Ferry (Pigott, 1959; https://blog.nms.ac.uk/2019/09/01/chasing-thecarnyx-from-scotland-to-the-saharal; acceso 11/03/2021). y su factura broncínea. En Celtiberia existen unos quince ejemplares de trompetas, pero en cerámica, de aspecto ultracircular a través de la espiral sobre sí misma de una tubería que en un extremo dispuso la embocadura y en el otro el altavoz (Sopeña, 1995: 104-109; 2012; Pastor, 1998: 92). Trabajos recientes han reconstruido varios especímenes, demostrando la factura en distintos tamaños y potencial -siempre en términos actuales- de unas tres octavas. Junto con su destino prístino para la guerra, cabría acaso suponer usos ceremoniales y la indicación de rango de tales objetos (Jiménez, 2012; Jiménez et al., 2018a y 2018b; http://www. emaproject.eu/content/instruments/numantiantrumpets.html; Romero et al., 2013: 83-87). Con personalidad formal respecto a los carnyces, su originalidad organística es parangonable por la magnífica decoración simbólica de algunas bocinas en forma de lobo (Green, 1992: 45, 91, 253; Lorrio, 
2007: 63; Manassero, 2013: 63; Hunter, 2019: 327). De los dos casos numantinos, uno exhibe el pabellón entero con la forma de la cabeza de la fiera, señalados nariz, orejas, ojos y dientes. En el segundo, una testa lobuna resalta totalmente del cuerpo. En la pieza termestina el megáfono entero adopta la forma del rostro amenazante del cánido. Y La Escondilla proporcionó otro altavoz, del s. I a. C., figurando al carnicero con fauces explícitas (Alfayé, 2004: 162-169). De las decoraciones pintadas, en concreto la doble espiral orientada hacia la salida del sonido ha sido relacionada con el aullido lobuno: una alegoría acústica (Fig. 10) (Pastor, 2010).

\section{Carnyx y plástica céltica}

La plasmación numismática del carnyx en la Céltica lo sobresignifica como autorrepresentación de las elites y emblema de la deidad (Swan, 2018). Las emisiones argénteas $c .51$ a. C. del eduo Dumnórix y las áuricas del catuvelauno Tasciovano, $c$. 20 a. C., resultan expresivas: en la medalla gala un hombre a pie,
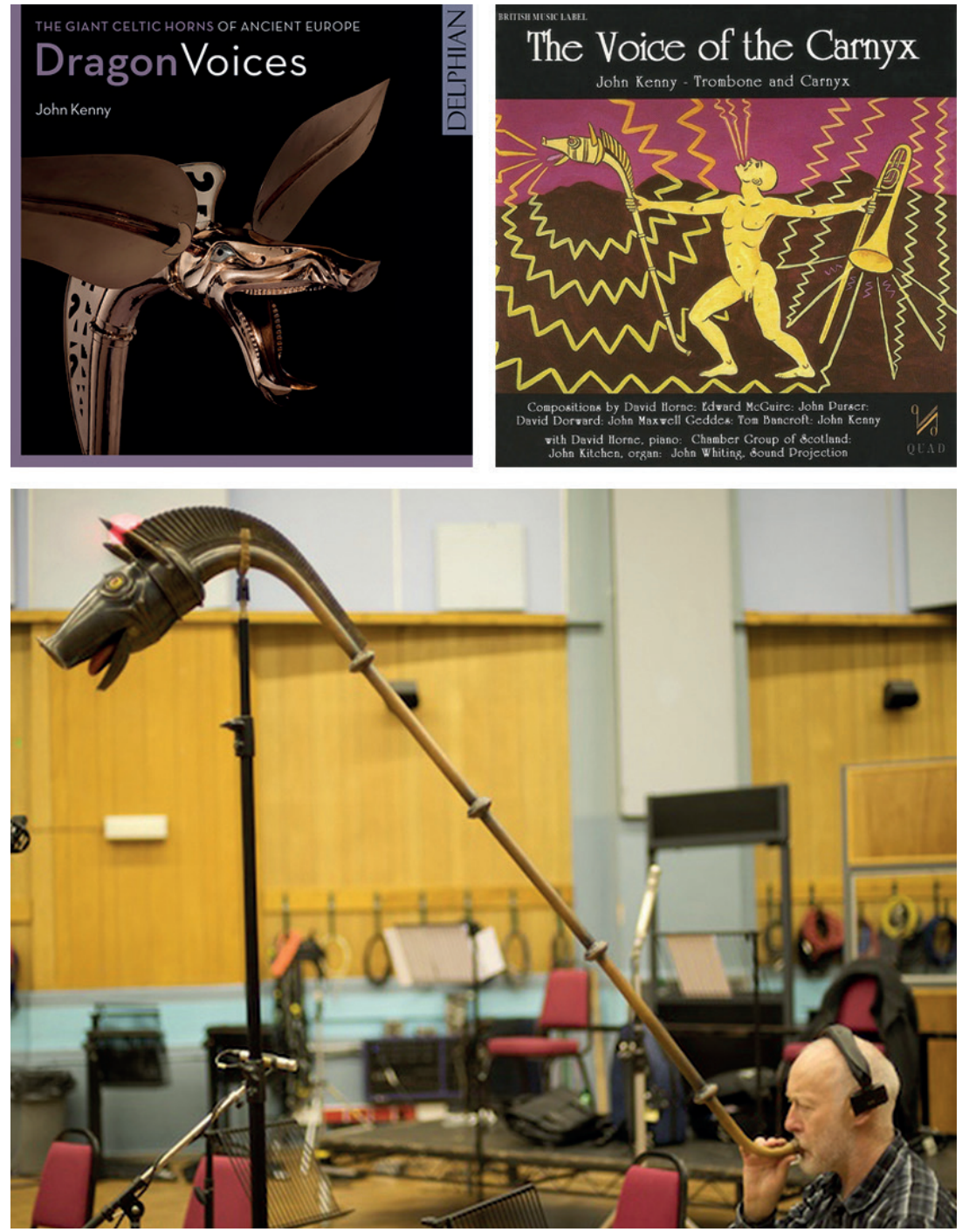

FIG. 3. Arriba: portadas de las composiciones para carnyx de John Kenny (The Voice of the Carnyx, BML, 1996 y Dragon Voices, Delphian, 2017); abajo: el maestro grabando con el reconstruido carnyx de Deskford en Abbey Road (http://www. michaelfassbender.org/soundc.html; acceso 18/06/2020).

con espada al cinto, porta una

insignia de jabalí en su mano izquierda y una cabeza cobrada en la contraria (Cassibry, 2017: 6); y en la pieza isleña, un jinete desnudo exhibe el carnyx en su diestra alzada junto a dos ruedas solares (Swan, 2016: 91. Cf. Rudd, 2010: 354, 387, 399, 2562, $2565,2568,2571,2676)$. Las monedas de los lemovices -que habitaron Tintignac- han brindado series con el tipo de un caballo de cuya boca parece surgir el relincho y bajo cuyo vientre hay un rostro humano. Junto al équido, un cuerno con bocina de cabeza de jabalí, quizá con lengua móvil. Las emisiones del rey de los cantiaci Dubnovellauno (Fig. 11), c. 20-10 a. C., ofrecen en su anverso un jabalí y en el reverso a una diosa desnuda con carnyx (Swan, 2016: 89; Hunter, 2019: 372-374). En suma, iconos nucleares de la ética céltica: la desnudez, la condición ecuestre, el arma, la decapitación, el sacro verraco (Sopeña, 2010: 246-247; Marco, 2007b). 


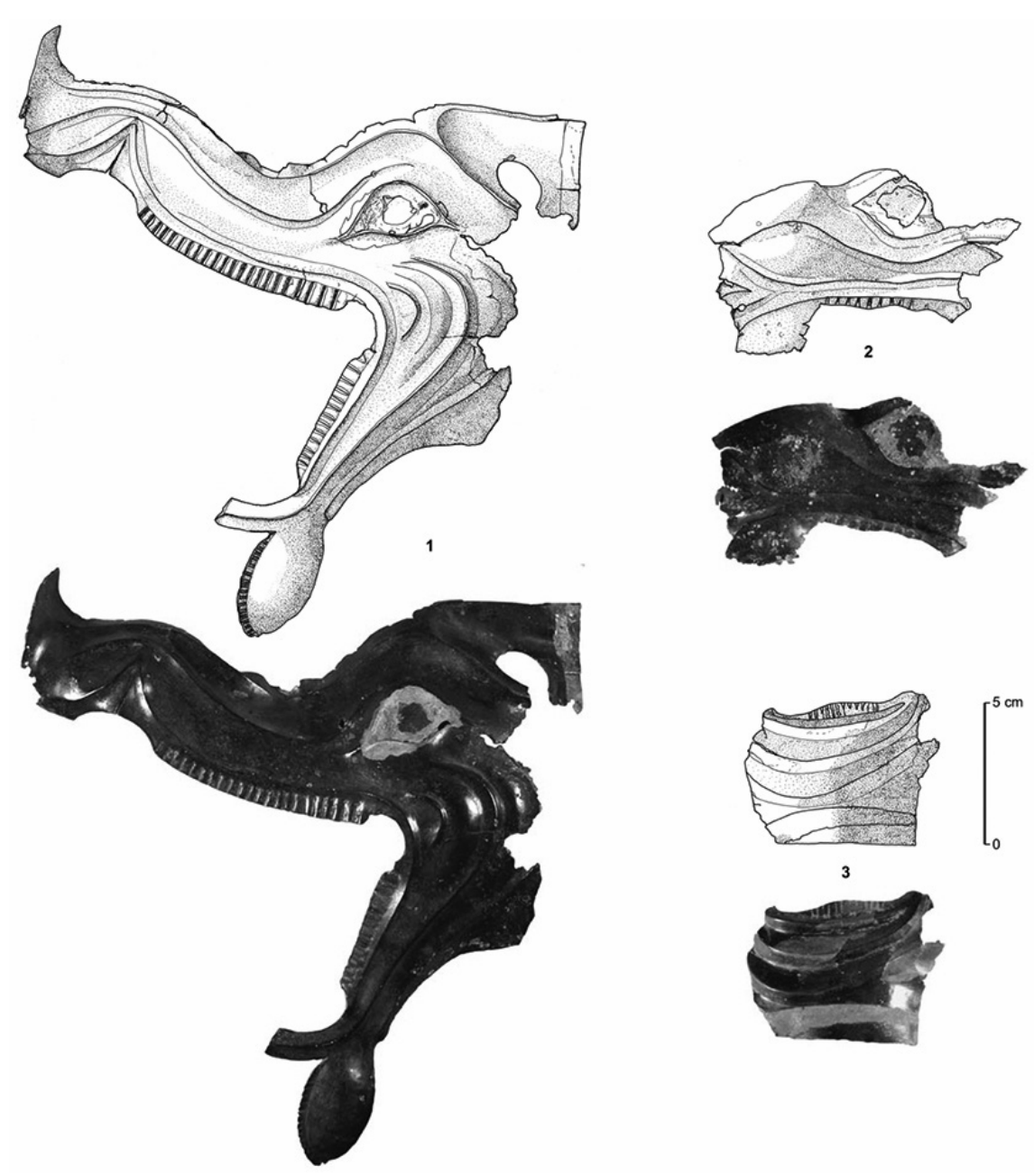

Fig. 4. Carnyx de Mandeure, Museo de Montbéliard (Barral et al., 2007: 388). de mayor talla que los demás comparecientes. A la izquierda, este introduce en un caldero custodiado por un lobo a los guerreros que caminan hacia él por el plano inferior; y de ahí resurgen, cabalgando engalanados hacia la derecha del superior, tras una serpiente cornuda. Un trío de salpistas - cuyas bocinas simulan feroces jabalíescierra la procesión abajo, al margen del área definida por el árbol: bajo el ofidio. Los intérpretes se disponen en el extremo diestro frente al gran sujeto que, junto al lobo, manipula el caldero en el siniestro: ambos conectan la escena, pues una línea horizontal uniría la cabeza de aquel con el amplificador de estos. Esta composición expresaría un tránsito escatológico mediante una estética bélica y fructificadora, con la inclusión del cuerno de guerra y la aparición del cornudo Cernunnos en otra
Los tipos monetarios pudieron ser imágenes públicas de representación identitaria también en Celtiberia. La ceca berona de Louitiscos, a mediados del s. II a. C., acuñó ases y semises (Fig. 12) con reverso de jinete tocado portando la trompeta bélica -de curva sencilla o en forma de s- en su hombro derecho (García-Bellido y Blázquez, 2001: 272-273; Hunter, 2009a: 241-242; Sopeña, 2012: 95-96).

De finales del s. II a. C., el caldero de Gundestrup plantea contundentemente la pregnancia simbólica de los carnyces en contexto (Vendries, 1999: 381383). Una de las placas interiores queda dividida en dos planos horizontales, separados por un árbol de la vida de tres raíces, que gestiona un personaje placa (Fig. 13) (Sopeña, 1995: 107-108, 118, 261; Brunaux, 2005: 237-238; Kaul, 2011).

Cabe aducir aún un texto de enconado escollo ecdótico, que referiría también este carácter trascendental de las salpinges célticas:

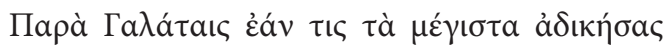

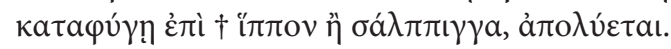

Entre los gálatas, si uno que ha cometido un delito muy grave apela a un caballo [¿o a sagrado?] o a una salpinge [¿̨o a una cueva?], queda libre.

(Paradoxógrafo Vaticano xLv. Keller, 1878: 112. Cf. Stern, 2008 = Admiranda, 44, 1; Hofeneder, 2011: 117-118. Traducción: Rodríguez Horrillo) 

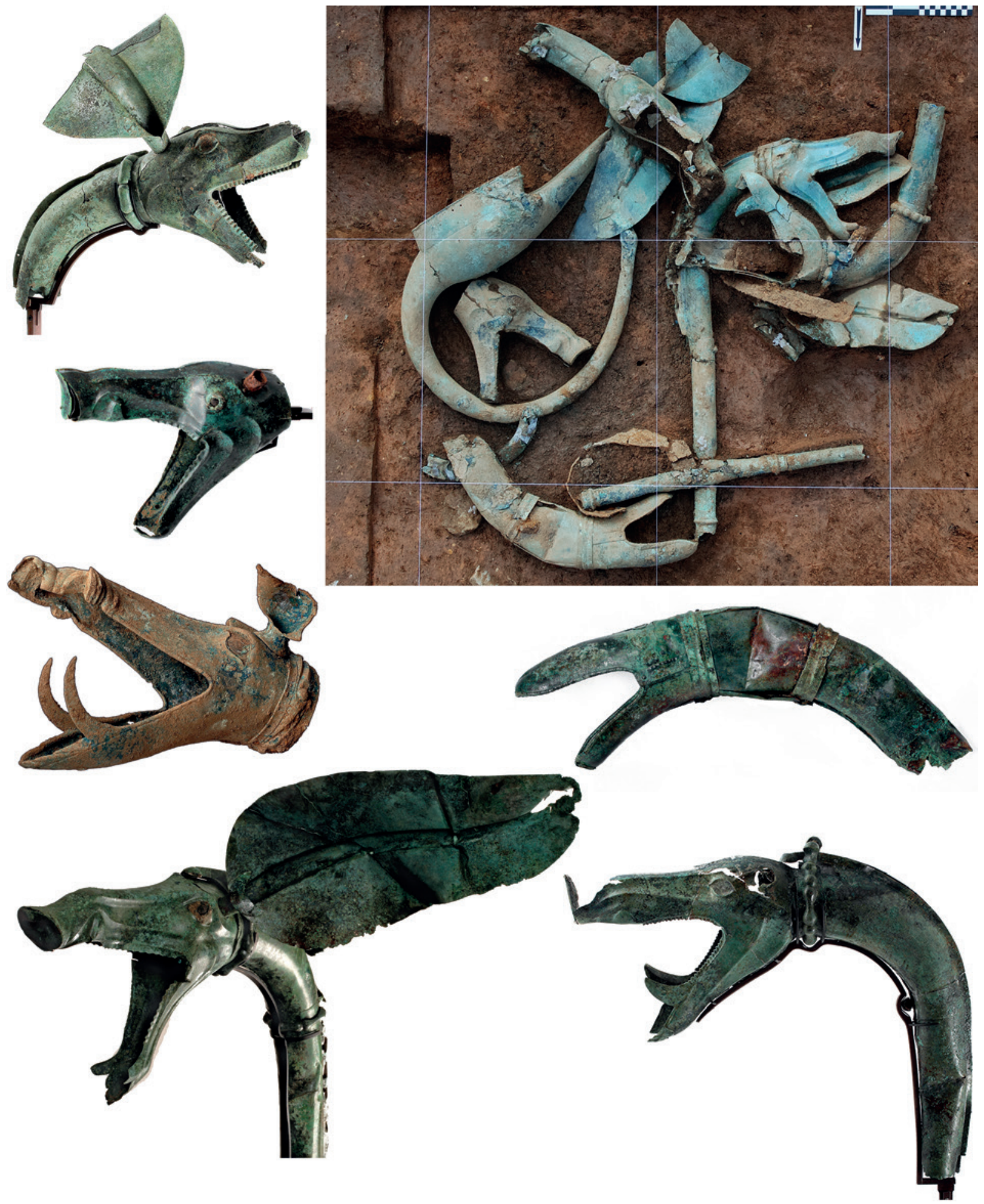

Fig. 5. Conjunto de Tintignac in situ y pabellones de los carnyces hallados. (@ Patrick Emaux, INRAP. https://www.imagesarcheologie.frl; acceso 11/03/2021). 


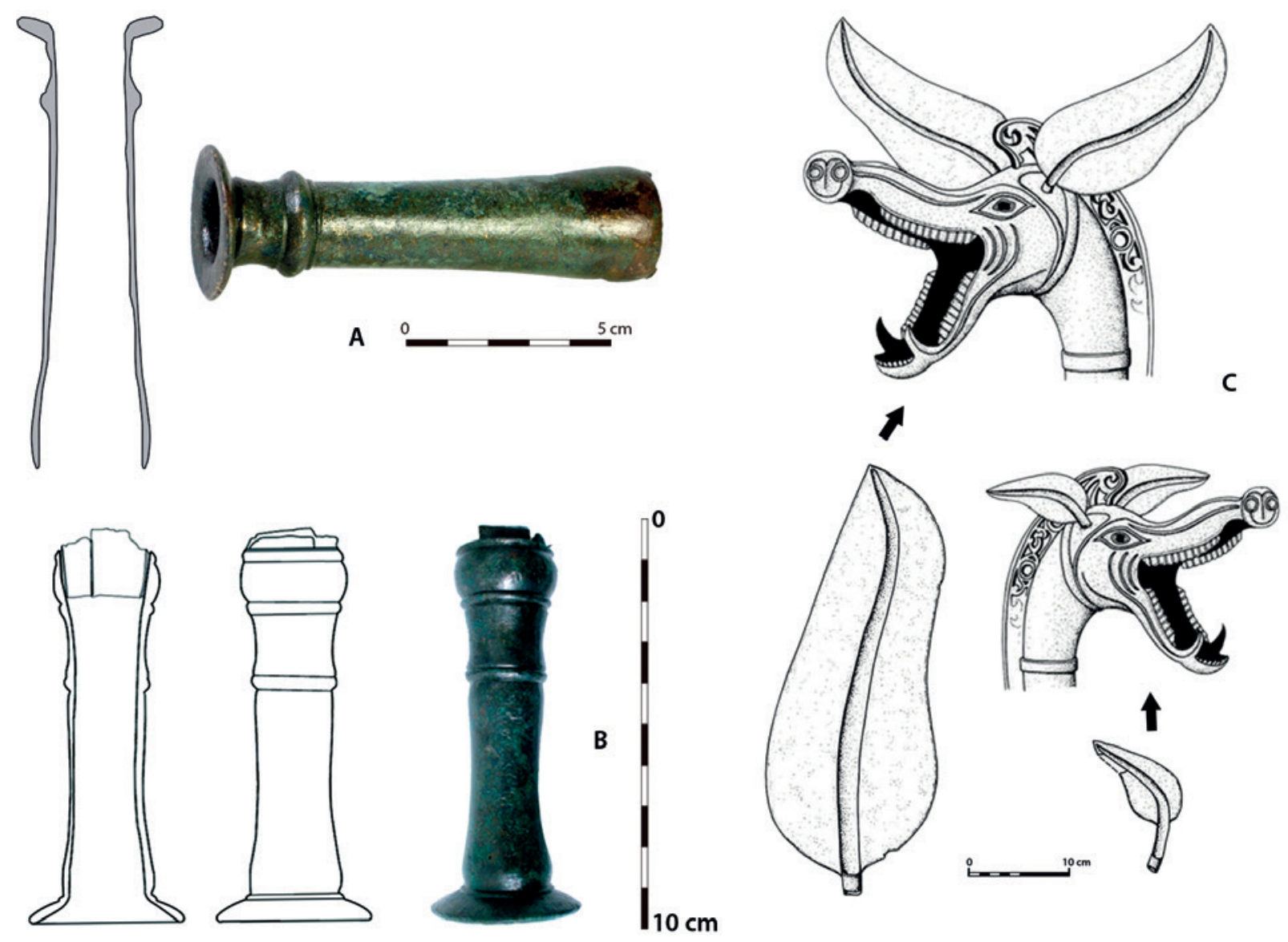

Fig. 6. Embocaduras de los carnyces de: A) Tignignac; B) Sanzeno (Maniquet et al., 2011: 87 y 104; Roncador, 2014: 166); C) reconstrucciones sobre los tipos de orejas fijadas a la bocina: Mandeure y Abentheuer (Hunter, 2009b: 76 y 79).

\section{Visiones externas contra autopercepción: feritas contra decorum}

El carnyx constituye una alusión iconográfica directa a la feritas y participó en la construcción del etnotipo bárbaro por antonomasia. Sin embargo, con ser tendente al descrédito, esta percepción asumida en la ecúmene grecolatina fue afinada y se atiene, sustancialmente, a la visión que de sí tuvieron las poblaciones célticas (Marszal, 2000; Frakes, 2005; Marco, 2007a y 2012; Kistler, 2009: 298-350; Marco y Sopeña, 2017: 143).

Los griegos asumieron la importancia ritual de los carnyces: una serie de tetradracmas etolias muestran a una mujer -personificación de la Liga- sobre tres escudos bárbaros y alanceando un cuerno gálata, recordando la resistencia frente a Macedonia y Breno en 314 y 279 a. C. (Fig. 14). Y así fueron patentizados en la stupa de Sanchi, India; en un ritón ebúrneo de Nisa, Turkmenistán; y en dos ungüentarios egipcios (Manassero, 2013; Hunter, 2019: 227-230, 555-557 y 566-569). El santuario de Atenea en Pérgamo, celebrando la victoria de Atalo I sobre los gálatas en 240 a. C., reprodujo diversos spolia; y acaso constaría el carnyx paflagonio eustaciano, con cabeza de novillo y lengua móvil (contra: Hunter, 2019: 625-26) (Fig. 15). El Gálata capitolino blasona esta valoración moral en su mármol, con la dignidad de un varón que agoniza serenamente, sintetizando los componentes de su barbarie 

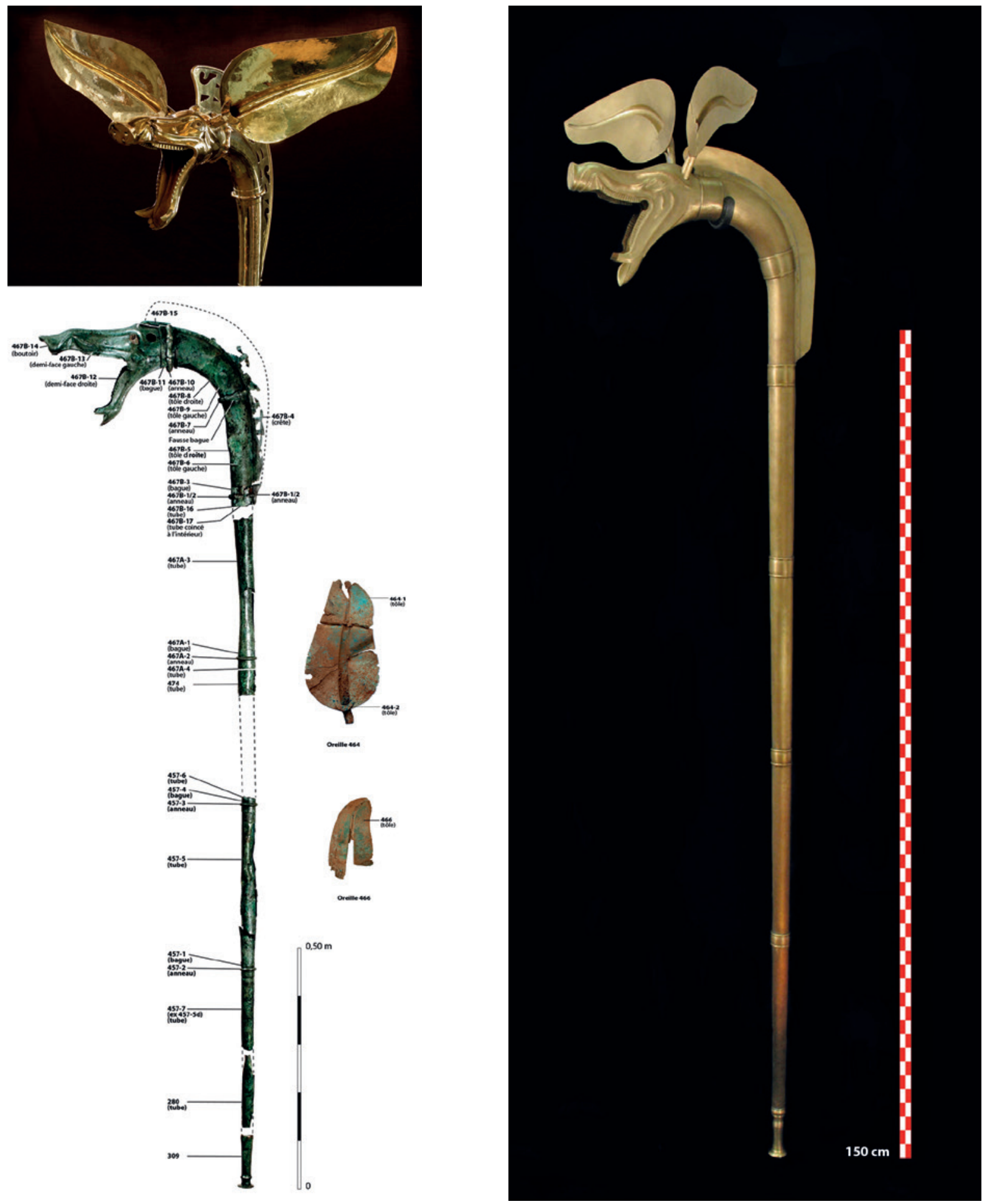

Fig. 7. Reconstrucción del carnyx de Tintignac (Maniquet et al., 2011: 71; (C) Patrick Emaux, INRAP. https:// www. images-archeologie.fr/; acceso 10/03/2021).

FIG. 8. Reconstrucción del carnyx de Sanzeno (Roncador, 2014: 175-176). 


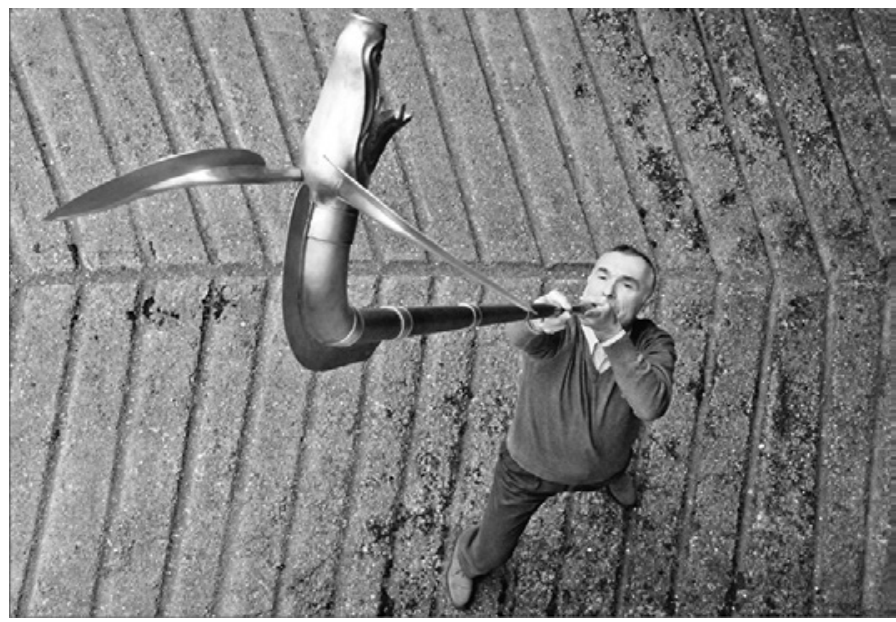

FIG. 9. El carnyx de Sanzeno, tocado por el maestro Ivano Ascari (Roncador, 2014: 177).

ante la Hélade: la desnudez, el torques, la espada y una trompeta rota, símbolo del valor acallado; y aunque esta no muestra altavoz animal -pues verosímilmente la copia romana 'tradujo', en deliberada metonimia (Marszal, 2000: 222-224; Marvin, 2002)-, esos elementos remiten al decorum céltico, en los antípodas del proceder helenístico (Mathieu, 2007; Marco, 2010b y 2012; Pernet, 2013; Cassibry, 2017). Un exvoto de bronce hallado en Hungría representa a un varón itifálico tocando un carnyx serpentiforme (Veres, 2009). Parco en detalles, la percepción del aerófono y el torques como única atribución, aparte de la viril desnudez, informa de qué modo los celtas consideraron el instrumento como esencial para su ethos: el mismo del que denigratoriamente dan cuenta las noticias e iconos grecolatinos (Fig. 16). Aun, la inclusión del carnyx en ajuares particulares, como consta en un pendiente de la necrópolis de Bouvay (Vendries, 1999: 370); y en una estatua de Pauvrelay que muestra a un torcuato de seis dedos en la mano portando un carnyx (Fig. 17A), evidencias todas de sacralidad (Coulon, 1990; Green, 2004: 180-182; Swan, 2018: 89).

El carnyx será manipulado por Roma como símbolo de la barbarie vencida, estandarizándose el instrumento en los tropaia desde Augusto: aunque dacios o sármatas desconocieran estos aerófonos, serán representados en la coraza de Domiciano o en la Columna y el Arco de Trajano (Polito, 1998: 122-190; Pernet, 2013). Como spolia celtica estarán mudos: un botín inerte que nadie toca. El Arco de Tiberio en Orange acopia nada menos que 37 carnyces existiendo innumerables representaciones en la iconografía triunfal (in extenso Hunter, 2019: 236-267, 423-551).

Particular interés revisten las acuñaciones republicanas conmemorando triunfos, exhibiendo al carnyx como estereotipo de los vencidos y paradigma de la feritas celtica ${ }^{2}$. Las emisiones narbonenses del 118 a. C. muestran un reverso con el tópico carro jupiterino, conducido por un galo desnudo con escudo, venablo y carnyx; pero la desnudez, los plaustros triunfales y el broquel 'traducido' como un ö $\pi \lambda$ o $v$ pertenecen plenamente al acervo de la Urbs: únicamente el cuerno de guerra define al auriga como un celta, símbolo de una Galia favorecida por Roma (Swan, 2016: 85-86). Avanzado el tiempo, el carnyx combinará con la biga o la Victoria; empero, ya en 48 a. C., con Décimo Junio Bruto, las gestas célticas se evocan con carnyces, aunque ya sin elementos romanos, en la idea de dominio pleno contra la alteridad: este mismo ańo, las piezas de Hostilio Saserna enseñan un carnyx junto a una mujer tristona y de ajado cabello, personificando a la Galia. En suma, esta iconografía monetal recolocaba a los celtas en la memoria popular, asegurando que la gran victoria de César permaneciese en el discurso público (Woytek, 2015; Swan, 2016: 86-88). Así, en las emisiones bilingües de Usekerte/Osicerda, un elefante aplasta un carnyx (Fig. 18D): ello sugiere la inspiración en las medallas antedichas, evocando a la Gallia Comata vencida e indicando influencias cesarianas en el gobierno ciudadano (Marco, 2010a: 80).

La coraza de Prima Porta pregona esta consideración del cuerno como quintaesencia céltica, sin ahorrar matices para perfilar iconográficamente la

2 Monedas de los años 206-200, 119, 118, 101, 98, $97,94,91,89,88,85,82,79,62$ y 51 a. C. $(R R C 128 ; 281$; $282 / 1-5 ; 332 ; 326 / 2 ; 333 ; 337 / 1 ; 343 / 2 b ; 344 / 3 ; 346 / 2$; 352/136/1a; 384; 412; 437/2-4 y 437/4a; 448; 450/1; 452/1-2,4-5; 468; 482; Hunter, 2019: 393-411). 

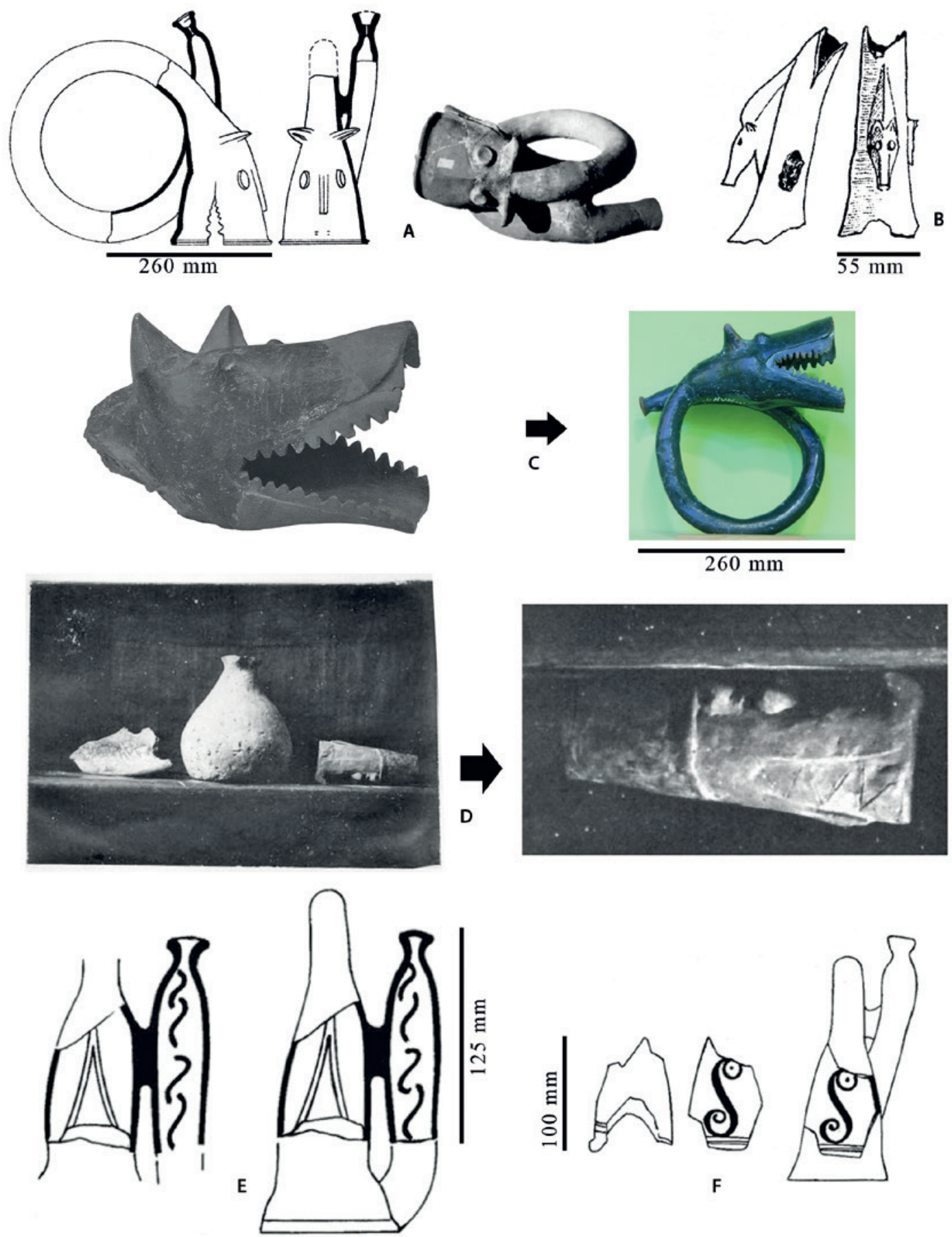

FIG. 10. Trompetas celtibéricas: A-B) de Numancia, en el Museo Numantino, n. ${ }^{\text {os }}$ inv. 8234 y 8226 (Sopeña, $1995:$ figs. 2526; imagen cortesía de A. Plaza); C) de Tiermes. en el MAN, n. ${ }^{\circ}$ inv. 1976/55/5; reconstrucción e imagen cortesía del ceramista C. Jimeno. Centro del Lobo Ibérico, Robledo de Sanabria; D) de La Escondilla (Alfayé, 2004: figs. 6-7); E-F) del Museo Numantino, pintadas con eses $-n .^{\circ}$ inv. 8241-y con doble espiral en la bocina, sin n. ${ }^{\circ}$ inv. (Pastor, 2010: fig. $1 \mathrm{~g}$ ). 

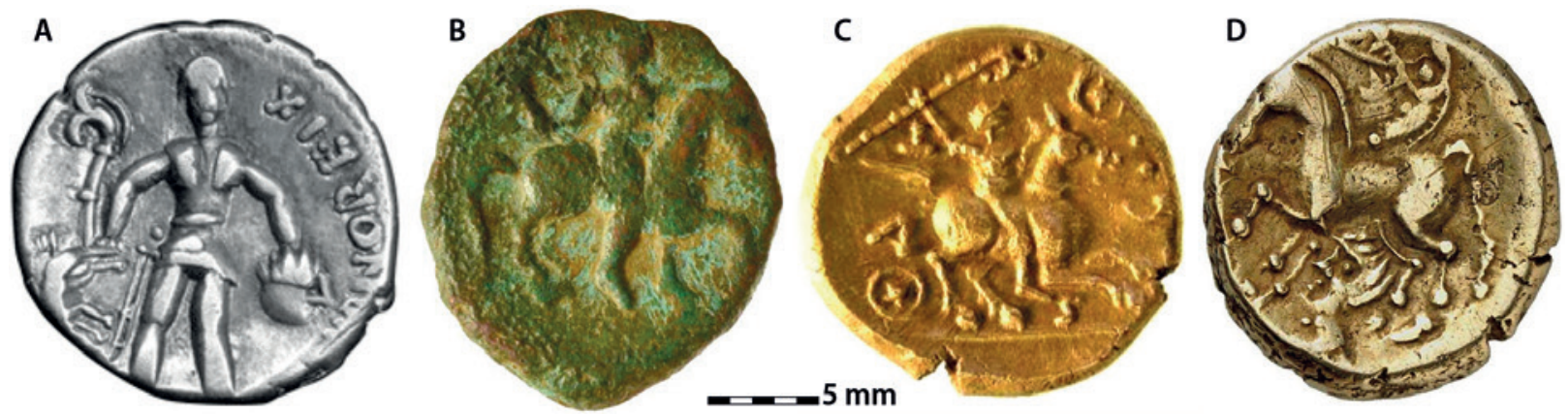

FIG. 11. Carnyces en reversos monetales: A) quinario de Dumnórix, c. 51 a. C. (Cassibry, 2017: 6); B) bronce de Dubnovellauno, c. 20-10 a. C. (Swan, 2016: 5); c) estátera de Tasciovano, c. 20 a. C. (Swan, 2016: 6); D) estátera de los lemovices, s. I a. C. (Société Numismatique du Limousin: http://www.snl87.fr/lemovices.htm; acceso 3/04/2020).

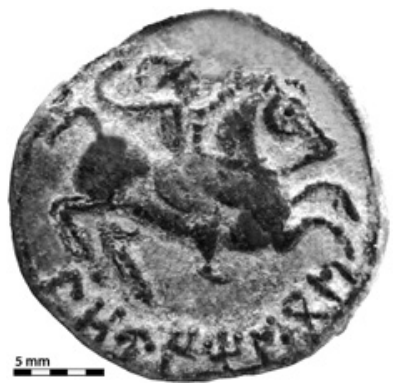

Fig. 12. Reverso de semis de Louitiscos, s. II a. C. (C) Colección Borges-Barreto).

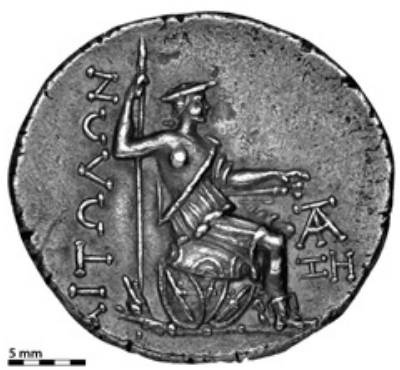

Fig. 14. Reverso de tetradracma de la Liga Etolia (Morton \& Eden. Catalogue 86, Auction 24/5/2017: 16; https://www.mortonandeden.com/past-auctions/; acceso 14/03/2020).

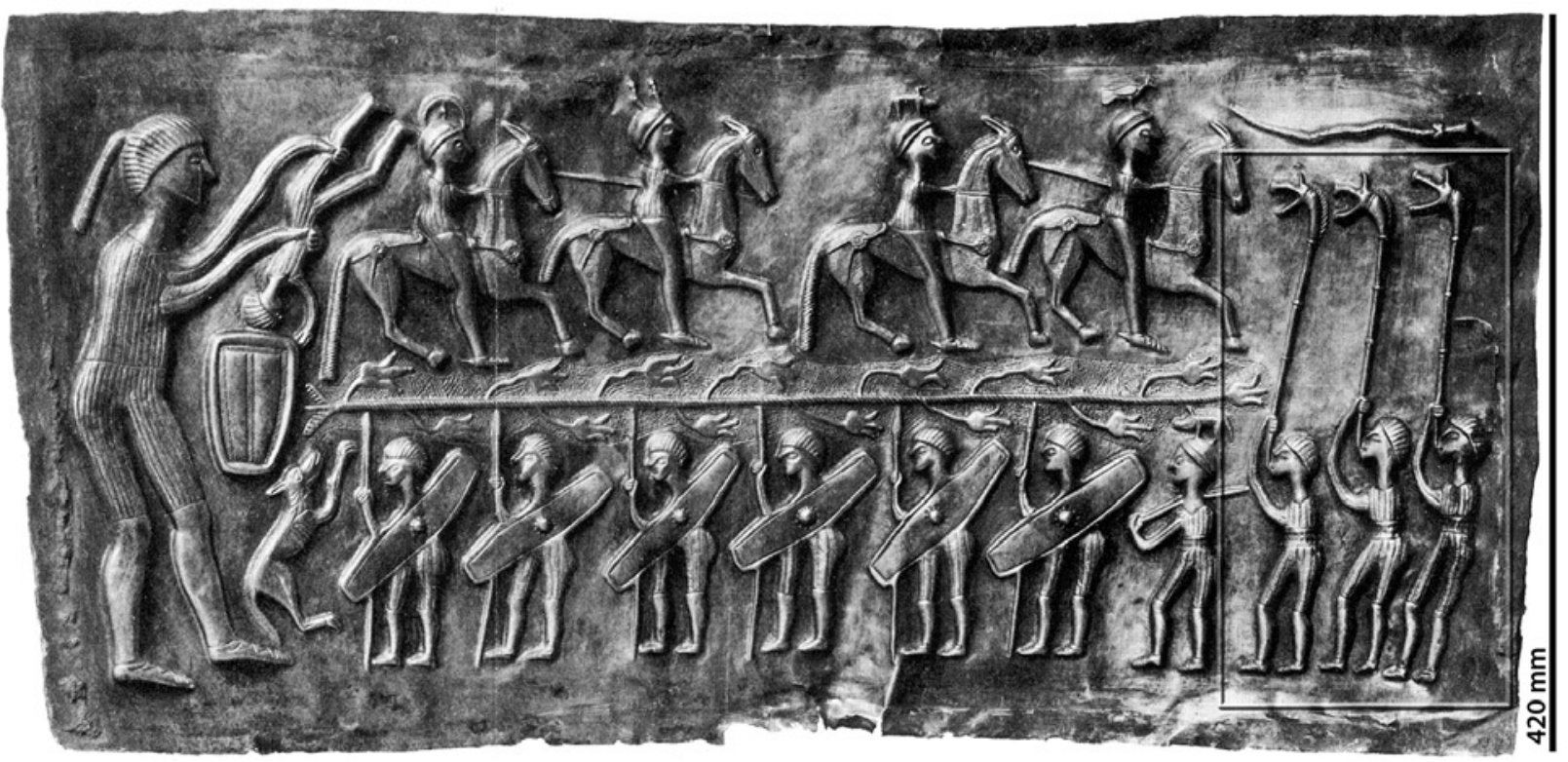

Fig. 13. Placa del caldero de Gundestrup, s. II a. C., en el Nationalmuseet, Danmark (Hachmann, R. 1990: fig. 9, n. ${ }^{\circ}$ 1); el trio de salpistas ha sido resaltado en la imagen mediante un rectángulo. 

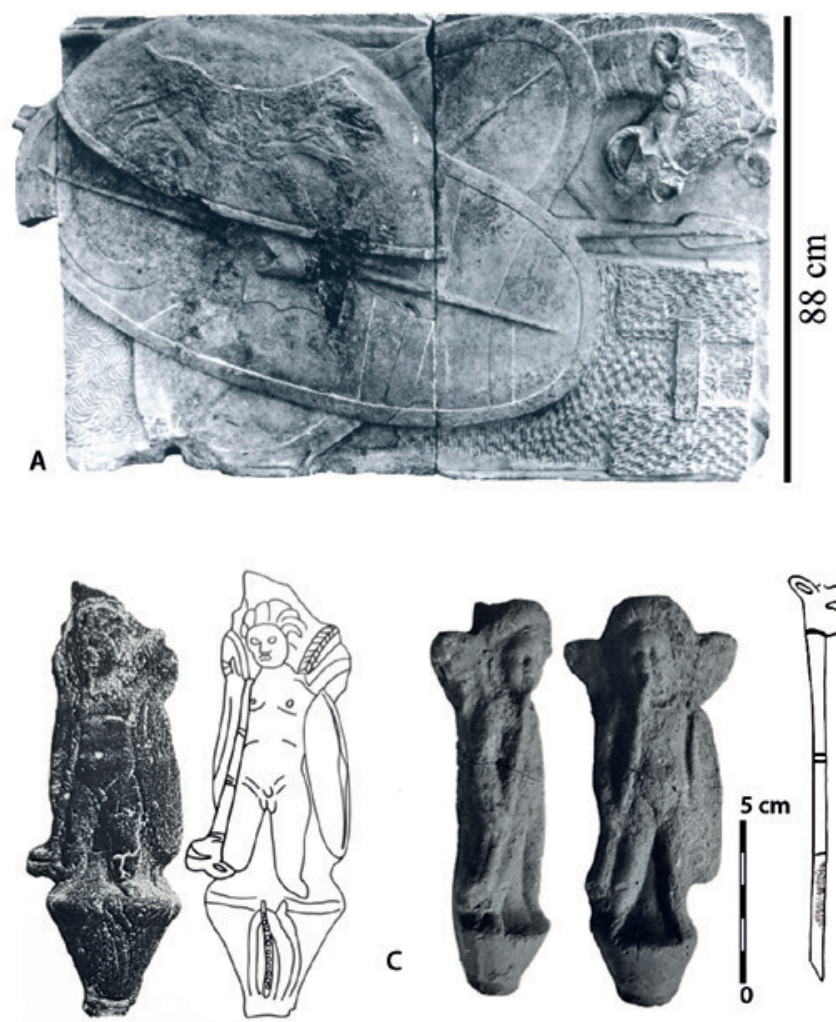

C
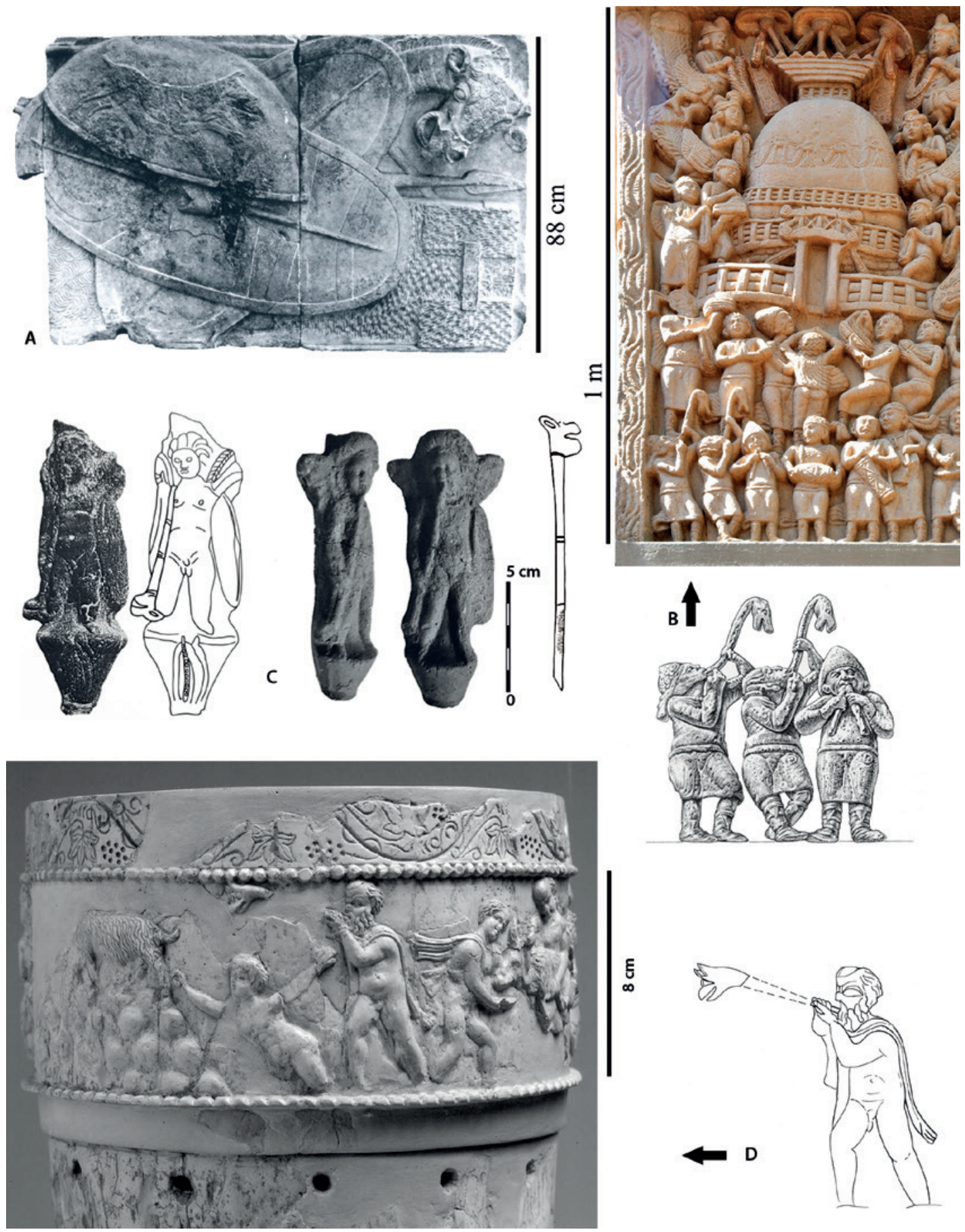

Fig. 15. A) Relieve de la balaustrada de la stoa del santuario de Atenea en Pérgamo; Pergamonmuseum, Berlín (Hunter, 2019: 625); B) intérpretes de carnyx en la cara oriental del pilar oeste de la torana norte de la Stupa de Sanchi, s. III a. C. (Wikimedia Commons; Veres, 2009: 238); C) ungüentarios de terracota procedentes de Egipto, s. III a. C., con Eros sobre flor de loto portando torques y escudo oval y sosteniendo carnyx con el pabellón orientado hacia el suelo (Hunter, 2019: 566); D) sátiro tocando un carnyx en ritón ebúrneo de Nisa, s. I a. C. (Manassero, 2013: fig. 2; https://blog.nms. ac.uk/2019/09/01/chasing-the-carnyx-from-scotland-to-the-saharal; acceso 11/03/2021). 
derrota bárbara, encajando la propaganda política de Augusto en un certero conocimiento. Galia, como mujer doliente, con bracae y una vaina vacía e inofensiva, utiliza al jabalí como distintivo de su sometimiento perfecto, ineluctable, triple: a sus pies, decorando un estandarte; en sus brazos, como pabellón del carnyx; pero significativamente también en el espal-

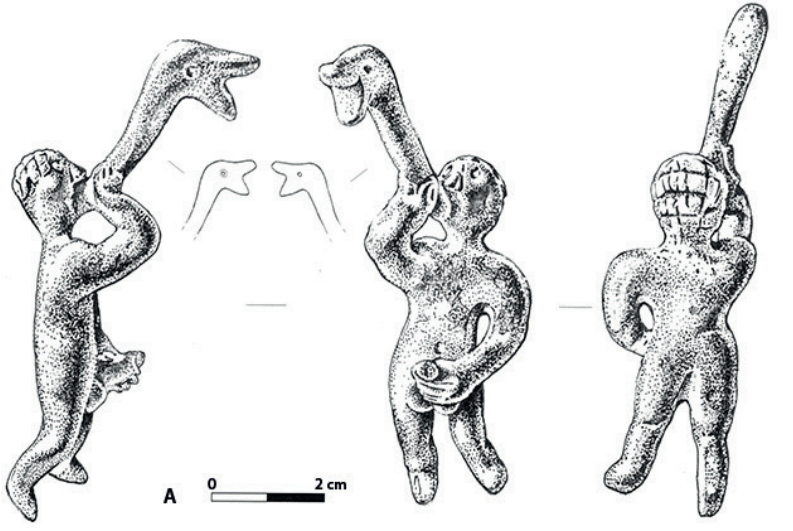

B

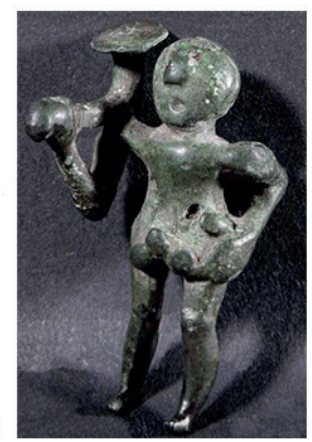

Fig. 16. Exvotos de bronce: A) hallado en Hungría, s. I a. C. (Veres, 2009); B) salpista con sexo erecto de Hradištè, República Checa; s. I a. C.; 4,8 cm de altura, Národni Muzeum, Praha (Megaw, 1991: 644).

dar, enfatizando el poder

intrínseco del instrumento (Zanker, 1988: 188-192;

Ostrowski, 1990; López, 2007: 128-132; Marco, 2007a y 2012; Hunter, 2019: 427-429) (Fig. 19).

\section{Acústica simbólica. Jabalíes, lobos, carnyces}

El jabalí es una bestia de inabarcable ubicuidad figurativa y altísima significación en la Céltica.

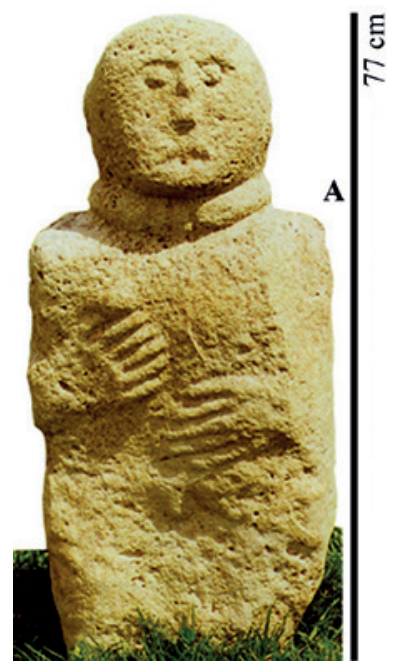

B

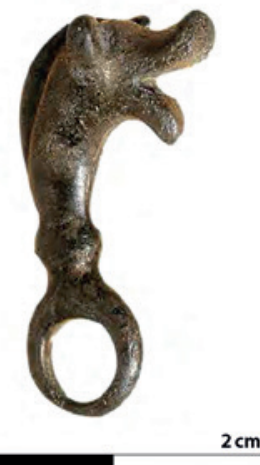

Fig. 17. Materiales galos: A) estatua-menhir de Pauvrelay, Indre-et-Loire (Bouquin y Deyts, 2014: fig. 8); B) colgante de la necrópolis de Bouvay (Vendries, 1993: 26).
Criatura impresionante -alcanza $300 \mathrm{~kg}$, resiste las heridas, tiene agresividad y capacidad para expresarla (Vendries, 1999: 378-381)- ha brindado etnónimos como "Cadurcos", *Catu- turci: 'puercos de combate', moradores del actual Quercy (Sergent, 1991: 10); y sus conexiones sacras son robustas, como aquí mismo ha sido señalado. Del torso de la escultura antropomorfa de Euffigneix -del s. II a. C., sin brazos, dotada de un ojo en cada costado, con torques- se destaca en relieve un jabalí: la intimidad entre suido y hombre en esta singular epifanía se ha relacionado con la participación del Ser en todos los estados, puntal del pensamiento céltico (Sopeña, 1995: passim; 2010: 262-63; Green, 2004: 130-135). Igualmente, una moneda de Esztergom (Hungría), del s. I a. C., exhibe una cabeza humana de perfil, con torques, de cuyo extremo superior surge un jabalí. El cabello erizado del sujeto, su gran ojo y una mano desmesurada inducen a pensar en una transformación desde lo humano a lo feral o viceversa (Green, 2004: 133-135, fig. 5, n. ${ }^{\text {os }} 11-12$ ): la metamorfosis del verraco en los textos vernáculos es harto frecuente. Allí la fiera despliega su índole ctónica vinculada con la realeza: en el relato galés Culhwch y Olwen, el jabalí Twrch Trwyth-Orc Treith, en irlandés- guarda los talismanes para los esponsales del héroe (Sterckxs, 1998). 

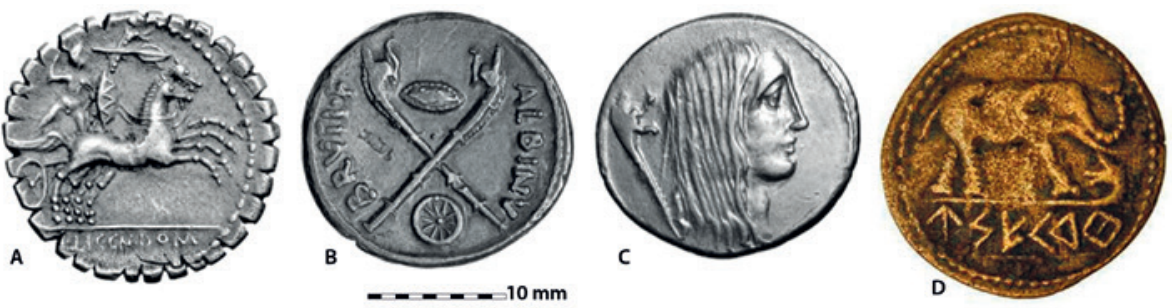

FIG. 18. Carnyces en monedas republicanas: A) reverso de denario serratus acuñado a nombre de L. LIC. CN. DOM en Narbo Martius; 118 a. C.; RRC 285/2 (Swan, 2016: 85, fig. 2): B) reverso de denario con spolia gallica acuñado a nombre de ALBINVS-BRVTI F. en Roma; 48 a. C.; RRC 450/1b (Swan, 2016: 87, fig. 4); C) anverso de denario acuñado a nombre del filocesariano L. HOSTILIVS-SASERNA en Roma; 48 a. C.; RRC 448/2a (Roma Numismatics Ltd. Auction xIV, 21/9/2017: 507. https://issuu.com/roma_ numismatics/docs/auction_xiv_web; acceso 4/11/2020); D) reverso de as bilingüe acuñado por Usekerte/Osicerda, mediados del s. I a. C.; DCPH 399, n. ${ }^{\circ} 1$ (Subastas Martí Hervera-Soler y Llach. Cat. 1083-2, 16/10/2014: F3233).

un radical ${ }^{*}$ Vailos alusivo a la fiera (Álvarez, 2003: 124-125).

Representado desde antiguo, su piel y sus dientes fueron manipulados en las tenerías y santuarios, como Villeneuve-Saint-Germain, Choisy-au-Bac o Digeon (Meniel, 1987: 79, 8993, 101-143; Green, 2004: 126). Antes de la adultez, se yacía en el suelo sobre pellejos; y quienes acudían al banquete

Por su parte, el lobo es uno de los protagonistas teriomorfos mejor caracterizado. Su vigoroso significado sombrío se compadece con entidades infernales; y lo vincula con los grupos de edad, encarnando el modelo de las fraternidades iniciáticas por doquiera (Grande, 1985; Sopeña, 1995: 109-119; Almagro, 1999; González-Alcalde, 2006; Moya, 2007). Expresa elocuentemente el misterio nocturno, la destreza venatoria, las ideas de invisibilidad, arrojo, sacrificio, resistencia, manada cooperante; $y$ destacó dentro del imaginario céltico en indisoluble parentesco semántico con el perro (Sergent, 1991: 33; Green, 2004: 135-140): ambos son designados en irlandés -y quizá en galo- por la palabra $C u ́$, antropónimo del campeón del Úlster, Cú Chulainn. De la etimología del gran cánido derivan antropónimos como Catuvolco, rey de los eburones. Aliado de Ambiórix contra César en el 54 a. C., se suicidó con veneno de tejo, incapaz para combatir a causa de su vejez (Guerra de las Galias, 6. 31. 5): su nombre está compuesto por *Catu, "combate", y *Volk, "lobo" (Sergent, 1991: 14; Delamarre, 2007: 237). Los volcas -tectósagos en Toulouse, arecómicos en Languedoc y volciani (Livio, 21.19.6) en Hispaniaacompañaron a Breno en el año 279: con étimo ${ }^{*}$ Volk son lobos, lo que concuerda con su carácter errante (Delamarre, 2003: 274-276; Marco, 2004: 91-93). El teónimo Vaelicus, documentado en las inscripciones de Postoloboso, también asienta en usaban para acomodarse pieles de cánidos (Diodoro, 5.32.7; Brunaux y Lambot, 1987: 49; Sopeña, 1995: 114). Su carácter ctónico destaca en los calderos: en el de Rynkeby, del s. II a. C. -afrontado a un jabalí, separados ambos por una tríscele (Green, 1992: 145)- y en el de Gundestrup, en el cual el lobo acompaña al gran personaje de la placa. Una moneda áurica de los Unelli armoricanos ilustra unos lobos prestos a devorar el sol y la luna, acompañados de un ave de presa y una serpiente; y otra muestra a un lobo encaramado a un caballo protegido por una tríscele, quizá aludiendo en ambos casos a una oposición entre fuerzas ctónicas y uránicas (Sopeña, 1995: n. 146; Green, 2004: 124-126; cf. Duval, 1987: 19-29). En la fíbula de Braganza hay una lucha entre el héroe y el cánido, que propicia el acceso al Allende (Marco, 2010c: 8). En suma, si la Tarasca de Noves constituyese la representación escatológica de un lobo, tal índole trascendental resaltaría a fortiori (Green, 1992: 150-151; Sopeña, 2010: 260-261).

Sucellos, forma continental del Dagda insular, fue asimilado por César con Dis Pater, ancestro de los celtas como hijos de la noche (Guerra de las Galias, 6. 18); y con aquel debería parangonarse esa deidad innominada a la que festejaban los celtíberos en los plenilunios (Estrabón, 3. 4. 16; Sopeña, 1995: 29-42). Es el único dios indígena figurado en una serie catalogable según convenciones clásicas: 
infernal y fecundo padre de la gente céltica, es plasmado como un hombre maduro, barbado y afable, con su martillo privativo, olla y tonel, siendo Nantosuelta su paredra (Deyts, 1992: 85-94). Destaca su atavío con pellejo de lobo, que avala su carácter umbrío y ctónico: los modelos de Viege (Genève) y Cairanne (Avignon) tienen tres cabezas (Sopeña, 1995: 116 y ss.; Olivares, 2002: 221-228). En armoricano, bleiz significa 'lobo'; y en el Medioevo Sucellos devino Saint Blaise: en la iglesia de Rozier-Côtes-d'Aurec (Loira), el santo luce un mazo e intimidad con el cánido (Baudet, 1987). La representación del joven e imberbe Entarabo -con epígrafes entre los treviros- mantuvo la librea lobuna y así se muestra en Noville-lez-Bastogne: acaso la cómoda asimilación del dios galo con Marte -Mars Intarabus, en un epígrafe del fanum de Leno Marte en Tréveris (CIL XIII, 3653) - potenciase su confraternidad con la bestia, puesto que también el lobo fue el emblema de la deidad romana (Van Andringa, 2002: 240).

La poesía nativa concede eminencia al animal. En el Táin bó Cuailnge Morrigan, despechada ante el rechazo del 'perro' Chulainn, se transforma sucesivamente en anguila, loba y novillo para incomodarle; algunos personajes -como Mongan, capitán del Ciclo Histórico- son consumados licántropos; y es notable la historia de Cormac Mac Airt quien, $c$. 227-266 d. C., estableció su corte en Tara. La muerte de su padre
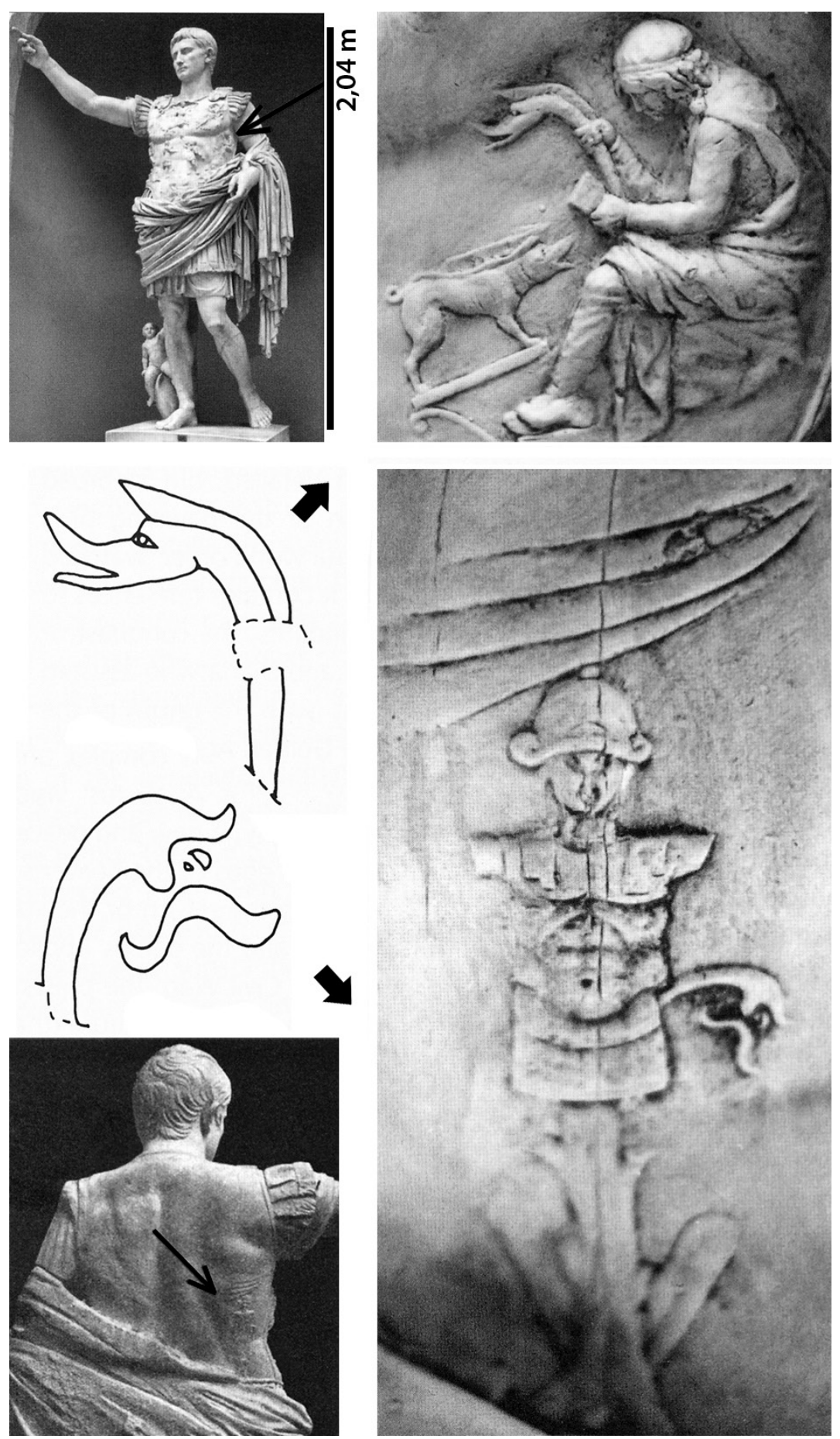

Fig. 19. Coraza de la estatua de Augusto de Prima Porta, Musei Vaticani, c. 2010 a. C.; dimensiones 2,08 $\times$ 0,12 $\times 1,3 \mathrm{~m}$. Galia sometida, personificada como mujer de lacios cabellos, bracae, carnyx con forma de cabeza de jabali, estandarte con un jabali de cuerpo entero a sus pies; $y$, en el espaldar, trofeo con casco, coraza y carnyx (Hunter, 2019: fig. 253 modificada). 
en la batalla de Magh Mucrama hizo escapar a su madre, Éachtach, ya encinta. En la huida dio a luz, pero el bebé Cormac fue raptado y criado por una loba. Creció feliz en la manada, se reintegró a la sociedad y gobernó virtuosamente (Alberro, 2005: 158-160, 182-183, 59-62). En definitiva, la literatura insular es prolija narrando metamorfosis de hombres en cánidos, así como la vinculación de individuos -sagrados o humanos- con la gran fiera (Green, 1992: 185-186, 192-193; Sopeña, 1995: 116; MacKillop, 1998).

Celtiberia dispensó favor particular al lobo. En 152 a. C. los nertobrigenses enviaron a Marcelo un heraldo ataviado con pellejo del animal: quizá representando a un grupo de edad que contravino -ignorante de ella- la decisión patria pactada con Roma (Apiano, Ibérica, 48; Sopeña, 1995: 109-119). Un fragmento cerámico numantino presenta a un hombre cubierto con la piel de la fiera (Sopeña, 1995: fig. 29); y en las acuñaciones de Sekaiza el cánido está asociado con jinete, retrato con torques y ave, con caballo o con Pegaso. El interesante repertorio de fíbulas y téseras lobunas celtibéricas incide, en fin, en idéntica consideración (Lorrio, 2007).

Jabalíes y lobos fueron escogidos por su potencia simbólica -que frecuentemente los aúna en el artepara decorar los altavoces de los aerófonos célticos de manera única en la organología. Sin embargo, debe valorarse también un elemento físico que informa del hondo carácter ético para el que tales artefactos estuvieron destinados.

El aullido es uno de los sonidos animales que mejor evocan la naturaleza salvaje, libre y auténtica. La voz del lobo incluye el saludo, el reclamo, la posesión: reivindica la territorialidad y sitúa a cada miembro de la manada. Audible a $10 \mathrm{~km}$ de distancia, su estructura sonora identifica a cada ejemplar -con su timbre único- y en conjunto a todo el grupo. Es una voz social: los lobos solitarios no delatan su ubicación, no aúllan; los cachorros y los adultos, sumisos o ansiosos, ladran; y el gruñido manifiesta niveles de tolerancia (Harrington y Asa, 2007: 66-79). Por su parte, los etólogos han catalogado al menos diez señales acústicas del jabalí, mediante las cuales se expresa el ánimo y la posición gregaria o

Ediciones Universidad de Salamanca / 요 preeminente. El rebudio es cotidiano; pero el alarido -combinado con la crin erizada y marcas odoríferas- demuestra dominio o militante defensa frente a las amenazas (Durantel, 2007: 47-52).

\section{Conclusión: carnyces y sacra dictio}

Durand (1981: 64) definía al animal como un 'abstracto espontáneo', arquetipo universal y objeto de caza o consumo. En la autopercepción identitaria mediante la apropiación imaginaria de la naturaleza, existe diferencia entre un objeto y su plasmación, puesto que los símbolos teriomorfos no existen aislados, sino que representan categorías nativas. Ante la dicotomía academicista 'bueno para comer' -Boas atque Radcliffe-Brown dicunt- frente a 'bueno para pensar' -Lévi-Strauss-, existe un postulado más adecuado a las religiones antiguas, basadas en la ortopraxis: los animales son 'buenos para sentir' pues promueven modelos de comprensión (Baker, 2001; Gilhus, 2006: 4-6).

Su ubicuidad en todos los aspectos de la multiforme y milenaria civilización céltica suscita debates sobre su función; pero acredita a las bestias como mediadores entre el aquí y el Allende, hipóstasis de las potencias sobrenaturales y de la divinidad, aparte de su índole sacrificial. El arte de los celtas normalmente es portátil y ligado a su cometido, resultando nuclear su trascender las convenciones de lo físico para desafiarlas y expresar a través de ellas conceptos infinitos mediante métodos finitos. Los animales encubren multitud de funciones y no se reducen a una sola: al igual que ocurre con los nombres de los dioses en la epigrafía.

Signo del poder por su bramido y su origen como cuerno, destinados originariamente para el ejercicio agonístico, el carnyx y la trompeta exteriorizaron un carácter formidable, sinónimo de la feritas para griegos y latinos. Pero los pueblos celtas distinguieron también sus aerófonos, como lo demuestra su condición de ofrendas y su plasmación en objetos solemnes. Por idéntica razón ética, estas gentes dieron a sus pabellones una apariencia animal, privativa en la historia de la organología. Su 
sonido en el ámbito marcial -donde vencer y morir arbitraron patrones sacrificiales- entrañó un sentido ritual vinculado con la divinidad que sancionaba el trance. Por ello, cabe aceptar también que tales decoraciones personificaron potencias ultramundanas (Brunaux-Lambot, 1987: 113-115; Ritchie y Ritchie, 1985: 25-31; Sopeńa, 1995: 108-109; 2012), invocadas o representadas mediante su epifanía animal en la boca del instrumento, asimilando el estruendo a una sacra dictio. La voz de la trompeta fue su propia voz: la voz a través del cuerno.

\section{Ediciones de las fuentes antiguas}

BekKer, I. (ed.) (1890): Diodori Bibliotheca historica. II. Leipzig: Teubner.

Büttner-Wobst, T. (ed.) (1922): Polybii Historiae. I. Leipzig: Teubner.

Conway, R. S. y Walters, C. F. (eds.) (1950): Titi Livii Ab urbe condita, libri XXI-XXV. Oxford: Clarendon.

Dindorf, W. (ed.) (1824): Iulii Pollucis Onomasticon cum annotationibus interpretum. Leipzig: Libraria Kuehniana.

Erbse, H. (ed.) (1975): Scholia Graeca in Homeri Iliadem (scholia vetera), IV. Berlin: De Gruyter.

Kaibel, G. (ed.) (1887-1890): Athenaei Naucratitae Dipnosophistarum, libri XV. Leipzig: Teubner (= Stuttgart, Teubner, 1962-1985).

Keller, O. (1878): Naturalium rerum Scriptores Graeci, I. Leipzig: Teubner.

Lasserre, F. (ed.) (1966): Strabon. Géographie. Paris: Les Belles Lettres.

LATte, K. (1953 y 1966): Hesychii Alexandrini Lexicon. I $(A-D)$, II (E-O). Copenhaguen: Munksgaard.

Mayhoff, C. (ed.) (1906): C. Plini Secundi Naturalis Historiae libri XXXVII. Leipzig: Teubner.

SeEl, O. (ed.) (1961): C. Iulius Caesar. Commentarii rerum gestarum. De bello gallico. Leipzig: Teubner.

VAN DER VAlK, M. (ed.) (1971, 1976, 1979 y 1987): Eustathii archiepiscopi Thessalonicensis. Commentarii ad Homeri Iliadem pertinentes ad fidem codicis Laurentiani editi: Praefationem et commentarios ad libros [Rho]-[Omega] complectens. (4 vols.). Leiden: Brill.

Viereck, P.; Roos, A. G. y Gabba, E. (eds.) (1962 = 1939): Appiani historia Romana, I. Leipzig: Teubner.

\section{Bibliografía}

Alberro, M. (2006): Paradigmas de la cultura y la mitología célticas. Ilustrados con sagas. Gijón: Trea.

Alfayé, S. (2004): “'La Escondilla': un posible yacimiento celtibérico en las proximidades de Peñalba de Villastar (Teruel)”. En Beltrán, F. (ed.): Antiqua Iuniora. En torno al Mediterráneo en la Antigüedad. Zaragoza: PUZ, pp. 155-171.

Alfayé, S. y Sopeña, G. (2010): "Imágenes del ritual e imágenes en el ritual en Celtiberia”. En Burillo, F. (ed.): Ritos y Mitos. VI Simposio sobre Celtíberos. Daroca: Fund. Segeda, pp. 455-472.

Almagro Gorbea, M. (1999): El rey lobo de la Alcudia de Elche. Alicante: Museo de la Univ. de Alicante.

Álvarez, J. (2003): Los señores del ganado. Madrid: Akal.

Amand, M. (1970): "Notes sur le culte du serpent criocéphale dans la cité des nerviens", Latomus, xxxıx, pp. 340-347.

BaKer, S. (2001): Picturing the beast: Animals Identity and Representation. Illinois: UIP.

Barral, P.; Bataille, G.; Bride, A.-S.; Guillaumet, J.-P.; Jaccottey, L.; Jeunot, L.; Ріснот, V. у SCHÖNFELDER, M. (2007): "Epomanduodurum, une ville chez les Séquanes. Bilan de quatre années de recherche à Mandeure et Mathay (Doubs)", Gallia, 64, pp. 353-434.

Baudet, J. (1987): “Essai d'Étude Mythologique: Négret et les Traditions relatives à Saint Blaise”, Bulletin et mémoires de la Société Archéologique et Historique de la Charente, 2, pp. 105-114.

Beltrán Lloris, F.; Jordán, C. y Marco, F. (2005): "Novedades epigráficas en Peñalba de Villastar (Teruel)", Palaeohispanica, 5, pp. 911-956.

Biel, J. I. (1991): "I principi celti del Baden Würtenberg”. En Moscati, S. (ed.): I celti. La prima Europa. Milano: Bompiani, pp. 108-113.

Bochnak, T. y Frankowski, P. (2010): "Brązowy aerofon z Malborka: carnyx, lituus czy olifant?”. En Urbaniak, A. y Prochowicz, R. (eds.): Terra Barbarica, II. Łódź-Warszawa: Monumenta Archaeologica Barbarica, pp. 179-196.

Bouquin, D. y DeYTs, S. (2014): "Une statuette inédite dans un contexte de sépulture secondaire à crémation gallo-romaine à Châlons-en-Champagne (Marne)", Revue archéologique de l'Est, 63, pp. 459-465.

Bren, J. (1991): "L'oppidum di Stradonice". En MosCATI, S. (ed.): I celti. La prima Europa. Milano: Bompiani, pp. 541. 
Briggs, S. (2014): "The Torrs Chamfrein or Headpiece: restoring 'A very curious relic of antiquity". En Gosden, C.; Crawford, S. y Ulmschneider, K. (eds.): Celtic Art in Europe: Making Connections. Oxford-Philadelphia: Oxbow, pp. 341-355.

Brunaux, J.-L. (2004): Guerre et religion en Gaule. Essai d'anthropologie celtique. Paris: Errance.

Brunaux, J.-L. (2005): Les gaulois. Paris: Les Belles Lettres.

Brunaux, J.-L. y Lambot, B. (1987): Armement et guerre chez les gaulois (450-52 av. J.C.). Paris: Errance.

Bundrick, S. D. (2005): Music and image in Classical Athens. Cambridge-New York: cup.

Burillo, F. (ed.) (2010): Ritos y Mitos. vi Simposio sobre Celtíberos. Daroca: Fund. Segeda.

Campbell, D. M y MacGillivray, T. (1998): "Reconstruction of the carnyx". En Proceedings International Symposium on Musical Acoustics (Leavenworth, WA). International Symposium of Musical Acoustics, 98. Cardiff, pp. 147-52.

Campbell, D. M y MacGillivray, T. (2000): "Acoustics of the carnyx". En Hickmann, E.; Laufs, I. y EICHMAnN, R. (dirs.): Studien zur Musikarchäologie II. Musikarchäologie Füher Metallzeiten. 1st Symposium of the International Study Group on Music Archaeology at Monastery Michaelstein, 1998. Rahden: Marie Leidorf, pp. 357-363.

Cassibry, K. (2017): "The Tyranny of the Dying Gaul: Confronting an Ethnic Stereotype in Ancient Art", Art Bulletin, 99, pp. 6-40.

Champion, C. (2000): "Romans as ßápßapot: Three Polybian Speeches and the Politics of Cultural Indeterminacy", Classical Philology, 95, pp. 425-444.

Clodoré-Tissot, T.; Le Gonidec, M.-B.; Ramseyer, D. y Anderes, C. (2009): Instruments sonores du Néolithique à l'aube de l'Antiquité. París: SpF.

Coles, J. M. (1963): "Irish Bronze Age horns and their relations with Northern Europe", Proceedings of the Prehistoric Society, 29, pp. 326-356.

Coulon, G. (1990): "Un nouveau personnage au torque dans le centre de la France, Pérassay (Indre)", Revue archéologique du Centre, 29, pp. 67-73.

Crawford, M. H. (1974): Roman Republican Coinage. Cambridge-New York: cup.

Creed, J. (2000): "Reconstructing the Deskford carnyx”. En Hickmann, E.; Laufs, I. y Eichmann, R. (dirs.): Studien zur Musikarchäologie II. Musikarchäologie Füher Metallzeiten. 1st Symposium of the International Study Group on Music Archaeology at Monastery
Michaelstein, 1998. Rahden: Marie Leidorf, pp. 347350.

De Bernardo, P. (2008): “сів. To Luguei 'hacia Lugus' frente a Luguei 'para Lugus': sintaxis y divinidades en Peñalba de Villastar”, Emerita, 76, pp. 181-196.

Delamarre, X. (2003): Dictionaire de la Langue Gauloise. Paris: Errance.

Delamarre, X. (2007): Noms des personnes celtiques. Paris: Errance.

Deyber, A. (2009): Les Gaulois en guerre. Stratégies, tactiques et techniques. Paris: Errance.

Deyts, S. (1992): Images des dieux de la Gaule. Paris: Errance.

Donaldson, G. H. (1988): "Signalling Communications and the Roman Imperial Army", Britannia, 19, pp. 349-356.

Durand, G. (1981): Las estructuras antropológicas de lo imaginario. Madrid: Taurus.

Durantel, P. (2007): Le sanglier et ses chasses. Chamalières: Artemis.

Duval, P.-M. (1987): Monnaies gauloises et mythes celtiques. Paris: Herrmann.

Eibner, A. (2013): "Zu den Schalltrichtern eisenzeitlicher Blechblasinstrumente. Vom Horn zur Karnyx". En Frass, M.; Breitwieser, R. y Nightingale, G. (eds.): Calamus: Festschrift für Herbert Graßl zum 65. Geburtstag. Philippika, 57. Wiesbaden: Harrassowitz, pp. 157-176.

Erdkamp, P. (2009): "Polybius, the Ebro Treaty, and the Gallic Invasion of 225 все”, Classical Philology, 104, pp. 495-510.

Fischer, F. (1991): "La tomba principesca de Kleinaspergle”. En Moscati, S. (ed.): I celti. La prima Europa. Milano: Bompiani, pp. 178-181.

Fleischinauer, G. (1964): Musikgeschichte in Bildern: Band 2, Musik des Altertums: Lieferung 5, Etrurien und Rom. Leipzig: Deutscher fur Musik.

Frakes, J. F. D. (2005): "An Architecture of Human Heads: Gallic Responses to Roman Power". En Aubert, J. J. y VÁrhelyi, Z. (eds.): A Tall Order. Writing the Social History of the Ancient World. München-Leipzig: De Gruyter, pp. 161-183.

Frey, O. H. y Szabó, M. (1991): "I celti nell'area balcanica”. En Moscati, S. (ed.): I celti. La prima Europa. Milano: Bompiani, pp. 478-484.

García-Bellido, M.a P. y Blázquez, C. (2001): Diccionario de cecas y pueblos hispánicos. Textos universitarios, 36. Madrid: Csic, vol. II. 
Georgiadou, A. (1998): "Eustathius and the Graeco-Roman Exegesis of Homer", Mnemosyne, 51, pp. 337-340.

Gilbert, J.; Brasseur, E.; Dalmont, J.-P. y ManiQUET, Ch. (2012): Acoustical evaluation of the Carnyx of Tintignac. Nantes: Société Française d'Acoustique.

Gilhus, I. S. (2006): Animals, Gods and Humans: Changing Attitudes to Animals in Greek, Roman and Early Christian Thought. London-New York: Routledge.

Gleirscher, P. (2014): "Fragments of a carnyx from Leisach (Austria)". En Gosden, C.; Crawford, S. y Ulmschneider, K. (eds.): Celtic Art in Europe: Making Connections. Oxford-Philadelphia: Oxbow, pp. 113-118.

González-Alcalde, J. (2006): "Totemismo del lobo, rituales de iniciación y cuevas-santuario mediterráneas e ibéricas", Quaderns de Prehistòria i Arqueologia de Castelló, 25, pp. 249-269.

Graells, R.; Lorrio, A. y Quesada, F. (2014): Cascos hispano-calcídicos. Simbolo de las élites celtibéricas. Mainz: RGZ.

Grande del Brío, R. (1985): El lobo ibérico. Biología y mitología. Madrid: Hermann Blume.

Green, M. J. (1989): Symbol and Image in Celtic Religious Art. London-New York: Routledge.

Green, M. J. (1992): Animals in Celtic Life and Myth. London y New York: Routledge.

Green, M. J. (2004): An Archaeology of Images. Iconology and Cosmology in Iron Age and Roman Europe. London-New York: Routledge.

Gricourt, D. y Hollard, D. (2010): Cernunnos, le Dioscure sauvage. Recherches comparatives sur la divinité des Celtes. Paris: L'Harmattan.

Hachmann, R. (1990): Gundestrup-Studien. Untersuchungen zu den spätkeltischen Grundlagen der frühgermanischen Kunst. Mainz: Von Zabern, pp. 565-903.

Hale, J. R. (2003): "Salpinx and Salpinktes: Trumpet and Trumpeter in Ancient Greece". En Basson, A. F. y Dominik, W. J. (eds.): Literature, Art, History: Studies on Classical Antiquity and Tradition in Honour of $W$. J. Henderson. Frankfurt am Main: Peter Lang, pp. 267-73.

Hansen, L. (2010): "Das späthallstattzeitliche Prunkgrab von Eberdingen-Hochdorf”. En Bofinger, J. y Krausse, D. (eds.): Aktuelle Forschungen zu den Kelten in Europa. Stuttgart: Theiss, pp. 69-82.

Harrington, F. H. y Asa, C. S. (2007): "Wolf Communication”. En Mench, D. L. y Boitani, L. (eds.): Wolves: Behavior, Ecology, and Conservation. Chicago-London: UchP.
Hickmann, E.; Laufs, I. y Eichmann, R. (dirs.) (2000): Studien zur Musikarchäologie II. Musikarchäologie Füher Metallzeiten. 1st Symposium of the International Study Group on Music Archaeology at Monastery Michaelstein, 1998. Rahden: Marie Leidorf.

Hickmann, E.; Laufs, I. y Eichmann, R. (dirs.) (2002): Studien zur Musikarchäologie III. Archäologie früher Klangerzengung und Tonordnung. Vorträge des 2. Symposiums der Internationalen Studiengruppe Musikarchäologie im Kloster Michaelstein, 2000. Rahden: Marie Leidorf.

Hofeneder, A. (2011): Die Religion der Kelten in den antikenliterarischen Zeugnissen. Sammlung. Übersetzung und Kommentierung, Band, III. Wien: Verlag der Österreichischen Akademie der Wissenschaften.

Homo-Lechner, C. y Vendries, C. (1993): Le Carnyx et la Lyre. Archéologie musicale en Gaule celtique et romaine. Catalogue d'exposition 1993-1994. Besançon: Musée des Beaux-Arts et d'Archéologie.

Hunter, F. (2000): "Reconstructing the carnyx". En Hickmann, E.; Laufs, I. y Eichmann, R. (dirs.): Studien zur Musikarchäologie II. Musikarchäologie Füher Metallzeiten. 1st Symposium of the International Study Group on Music Archaeology at Monastery Michaelstein, 1998. Rahden: Marie Leidorf, pp. 341345.

Hunter, F. (2001): "The Carnyx in Iron Age Europe", The Antiquaries Journal, 81, pp. 77-108.

Hunter, F. (2009a): "The carnyx and other trumpets on Celtic coins". En Van Heesch, J. y Heeren, I. (eds.): Coinage in the Iron Age, Essays in honour of S. Scheers. London: Spink, pp. 230-248.

Hunter, F. (2009b): "Une oreille de carnyx découverte à La Tène". En Honegger, M.; Ramseyer, D.; KaeNel, G.; Arnold, B. y Kaeser, M.-A. (dirs.): Le site de La Tène: bilan des connaissances-état de la question. Archéologie neuchâteloise, 43. Neuchâtel: Musée Cantonal d'Archéologie, pp. 75-86.

Hunter, F. (2019): The carnyx in Iron Age Europe: the Deskford carnyx in its European context. Mainz: RGZ. ICLP = Moscati, 1991.

Jiménez Pasalodos, R. (2012): "The archaeology of the musical performance: the example of Second Iron aerophones". En Company, G.; Fonte, J.; Gómez-Arribas, B.; Moragón, L. y Señorán, J. M. (eds.): Arqueología para el siglo XXI. Actas V Jornadas de Jóvenes Investigadores en Arqueología. Madrid: JAS Arqueología, pp. 181-186.

Jiménez Pasalodos, R.; Agua, R.; Padilla, J. J.; VILlegas, M.a Á. y García, M. (2018a): "Estudio 
acústico, arqueométrico y musicológico de instrumentos musicales arqueológicos: las trompetas de cerámica de Numancia (siglos III-I a. C.)", Anuario Musical, 72, pp. 9-22.

Jiménez Pasalodos, R.; García Benito, C. y Padilla, J. J. (2018b): "Las trompetas numantinas: aproximación a su estudio acústico en una cocción experimental con una reproducción de un horno de la Segunda Edad del Hierro". En Actas 3.er Congreso Internacional de Arqueología Experimental (Banyoles, 2011). Barcelona: MAC, pp. 387-395.

Kaul, F. (2011): "The Gundestrup Cauldron. Thracian Art, Celtic Motifs", Études Celtiques, 37, pp. 81-110.

Kaul, F. y Martens, J. (1995): "Southeast European Influences in the Early Iron Age of Southern Scandinavia. Gundestrup and the Cimbri”, Acta Archaeologica, 66, pp. 111-161.

Kenny, J. (2000): "Reconstruction of the Deskford Carnyx-An Ongoing Multidisciplinary Project". En Hickmann, E.; Laufs, I. y Eichmann, R. (dirs.): Studien zur Musikarchäologie II. Musikarchäologie Füher Metallzeiten. 1st Symposium of the International Study Group on Music Archaeology at Monastery Michaelstein, 1998. Rahden: Marie Leidorf, pp. 351356.

Kimmig, W. (1998): Das Kleinsapergle. Forschungen und Berichte zur Vor und Frühgeschichte in Baden-Württemberg, 30. Stuttgart: Theiss.

KIsTLER, E. (2009): Funktionalisierte Keltenbilder: die Indienstnahme der Kelten zur Vermittlung von Normen und Werten in der hellenistischen Welt. Berlin: Antike.

Krausse, D. (1996): Hochdorf III: Das Trink- und Speiseservice aus dem späthallstattzeitlichen Fürstengrab von Eberdingen-Hochdorf (Kr. Ludwigsburg). Forschungen und Berichte zur Vor-und Frühgeschichte in Baden-Württemberg. Stuttgart: Theiss.

Krentz, P. (1993): “The Salpinx in Greek Warfare”. En Davis Hanson, V. (ed.): Hoplites: The Classical Greek Battle Experience. Abingdon-New York: Routledge, pp. 110-120.

Kruta, V. (2013): "Les bronzes de Castiglione delle Stiviere: carnyx ou effigie d'un échassier?", Études Celtiques, 39, pp. 41-60.

LAING, L. y LAING, J. (1984): "Archaeological notes on some Scottish early Christian sculptures”, Proceedings of the Society of Antiquaries of Scotland, 114, pp. 277287.

Landels, J. G. (2000): Music in ancient Greece and Rome. London-New York: Routledge.
Lejeune, M. (1985): Recueil des Inscriptions Gauloises. Vol. 1: Textes gallo-grecs. XIv Supplément à Gallia. Paris: CNRS.

López, D. G. (2007): “Before your Very Eyes. Roman Imperial Ideology, Gender Constructs and Paul's Inter-Nationalism". En Penner, T. C. y Vander StiCHELE, C. (eds.): Mapping gender in ancient religious discourses. Leiden: Brill, pp. 115-162.

Lorrio, A. (2007): "Una fíbula simétrica del Museo Arqueológico Municipal de Lorca y las fíbulas lobunas celtibéricas", Alberca, 5, pp. 53-66.

Lorrio, A. y Royo, J. I. (2013): "El guerrero celtibérico de Mosqueruela (Teruel): una pintura rupestre excepcional de la Edad del Hierro en el Alto Maestrazgo turolense", Antiquitas, 25, pp. 85-108.

MacDonald, P. (2007): Llyn Cerrig Bach: a study of the copper alloy artefacts from the insular La Tène assemblage. Cardiff: UwP.

MacKillop, J. (1998): The Oxford Dictionary of Celtic Mythology. Oxford: oup.

Maier, F. (1991): "Gli oppida celtici”. En Moscati, S. (ed.): I celti. La prima Europa. Milano: Bompiani, pp. 411-425.

Manassero, N. (2013): "Celto-Iranica. The Strange Case of a Carnyx in Parthian Nisa", Etudes Celtiques, 39, pp. 61-86.

Maniquet, C. (2008): "Le dépôt cultuel du sanctuaire gaulois de Tintignac à Naves", Gallia, 65, pp. 273326.

Maniquet, C.; Adamski, F.; Armbruster, B. R.; Drieux, M.; Espinasse, L.; Lejars, T. y Mora, P. (2009): Les guerriers gaulois de Tintignac. Limoges: Éditions Culture et Patrimoine en Limousin.

Maniquet, C.; Lejars, T.; Ambruster, B.; Pernot, M.; Drieux-Daguerre, M.; Mora, P. y Espinasse, L. (2011): "Le carnyx et le casque-oiseau de Tintignac (Naves-Corrèze). Description et étude technologique", Aquitania, 27, pp. 63-150.

Marco, F. (1993): "Feritas Celtica: Imagen y realidad del bárbaro clásico”. En Falque, E. y Gascó, F. (eds.): Modelos ideales y prácticas de vida en la Antiguedad clásica. Sevilla: UIMP, pp. 141-166.

Marco, F. (1997): "Vestius Aloniecus". En Lexicon Iconographicum Mythologiae Classicae. Artemis, viII.1. Zürich-München-Düsseldorf.

Marco, F. (1998): "Heroización y tránsito acuático: Sobre las diademas de Mones (Pilońa, Asturias)". En Alvar, J. y Mangas, J. (eds.): Homenaje a J. M. Blázquez. Madrid: Ediciones Clásicas, vol. II, pp. 319-348. 
Marco, F. (2002): "Diis Deabusque. A indefinição primordial do divino”. En Ribeiro, J. C. (coord.): Religióes da Lusitânia-Loquuntur Saxa. Lisboa: MNA, pp. 17-19.

Marco, F. (2003): “Signa Deorum: Comparación y contexto histórico en Hispania y Galia”. En Tortosa, T. y Santos, J. A. (eds.): Arqueología e Iconografia: Indagar en las imágenes. Roma: L'Erma di Bretschneider, pp. 121-136.

Marco, F. (2004): "Acerca de las migraciones célticas a la Península Ibérica”. En Marco, F.; Pina, F. y Remesal, J. (eds.): Vivir en tierra extraña: migraciones e integración cultural en el mundo antiguo. Barcelona: uB, pp. 77-93.

Marco, F. (2006): “Mars Tricornis des Pyrenées". En Brouquier-Reddé, V.; Bertrand, E.; L’Huillier, M.-C.; Chardenoux, M. B.; Gruel, K. y Bérard, F. (eds.): Mars en Occident. Rennes: PuR, pp. 97-104.

Marco, F. (2007a): “¿De la feritas a la fides?: identidad, alteridad y transformación identitaria en el mundo romano-céltico del occidente del Imperio". En MaNgas, J. y Montero, S. (eds.): Ciudadanos y extranjeros en el mundo antiguo: segregación e integración. Madrid: Ediciones 2007, pp. 85-109.

Marco, F. (2007b): "Celtic Ritualism from the (Graeco)-Roman Point of View”. En Scheid, J. (ed.): Rites et croyances dans les religions du monde Romain. Vandoeuvres-Genève: Fondation Hardt, pp. 149-188.

Marco, F. (2009): "Vino, ritual y poder en el mundo céltico". En SAnz, C. y Romero, F. (eds.): El vino y el banquete en la Europa prerromana. Valladolid: Univ. de Valladolid, pp. 81-92.

Marco, F. (2010a): "Hommes et images: rapports entre la Gaule et la Tarraconensis entre le s. II avant J. C. et le s. Iv après J. C.". En Pons Pujol, L. (ed.): Hispania et Gallia. Dos provincias del Occidente romano. Barcelona: UB, pp. 79-91.

Marco, F. (2010b): "On the Confrontation and cultural integration of the Celts in the western Roman Empire”. En Bohry, L. (dir.): Studia Celtica classica et Romana Nicolae Szabó septuagesimo dedicata. Budapest: Pytheas, pp. 151-158.

Marco, F. (2010c): "Dioses, espacios sacros y sacerdotes". En Burillo, F. (ed.): Ritos y Mitos. VI Simposio sobre Celtíberos. Daroca: Fund. Segeda, pp. 1-13.

Marco, F. (2012): "Iconografía de la derrota: formas de representación del bárbaro occidental en época tardorrepublicana y altoimperial". En Marco, F.; Pina, F. y Remesal J. (eds.): Vae victis! Perdedores en el mundo antiguo. Barcelona: UB, pp. 177-195.
Marco, F. y Sopeña, G. (2017): "La religión en la Celtiberia: de las divinidades a la ideología funeraria". En Jimeno, A. (ed.): Numancia eterna. 2150 aniversario: la memoria de un simbolo. Salamanca: JCYL, pp. 127154.

Marszal, J. R. (2000): “Ubiquitous Barbarians. Representations of the Gauls at Pergamon and Elsewhere". En De Grummond, N. T. y Ridgway, B. (eds.): From Pergamon to Sperlonga: Sculpture and Context. Berkeley: UCP, pp. 191-234.

Marvin, M. (2002): "The Ludovisi Barbarians: The Grand Manner". En Gazda, E. K. (ed.): The Ancient Art of Emulation: Studies in Artistic Originality and Tradition from the Present to Classical Antiquity. MAAR Suppl. vol. 1. Roma, pp. 205-223.

Mathieu, F. (2007): Le guerrier gaulois: Du Hallstatt à la conquête romaine. Paris: Errance.

Mazzinı, G. (2008): "La bucina e il bucinator nelle forze armate di Roma”. En Caldelli, M. L.; Gregori, G. L. y Orlandi, S. (eds.): Epigrafia 2006. Atti XIV Rencontre sur l'Épigraphie in Onore di Silvio Panciera, 3. Roma: Quasar, pp. 1197-1226

Megaw, J. V. S. (1991): "La musica celtica". En MosCati, S. (ed.): I celti. La prima Europa. Milano: Bompiani, pp. 643-648.

Moscati, S. (ed.) (1991): I celti. La prima Europa. Milano: Bompiani.

Moya, P. (2007): "Ritos de paso y fratrías en la Hispania Céltica: a propósito de los tunos de Segóbriga”. En Sainero, R. (coord.): Pasado y presente de los Estudios Celtas. La Coruña: Fundación Ortegalia-Instituto de Estudios Celtas, pp. 169-242.

Nelson, M. (2008): The Barbarians Beverage. A History of Beer in Ancient Europe. London-New York: Routledge.

Nooter, S. (2019): "The War-Trumpet and the Sound of Domination in Ancient Greek Thought", Greek and Roman Musical Studies, 7, pp. 235-249.

O'Dwyer, S.; Kenny, J. y Creed, J. (2002): “A Trumpa Créda. Construction and Exploration”. En Hickmann, E.; Laufs, I. y Eichmann, R. (dirs.): Studien zur Musikarchäologie III. Archäologie früher Klangerzeugung und Tonordnung. Vorträge des 2. Symposiums der Internationalen Studiengruppe Musikarchäologie im Kloster Michaelstein, 2000. Rahden: Marie Leidorf, pp. 194-204.

Olivares, J. C. (2002): Los dioses de la hispania céltica. Alicante: RAH. 
Ostrowski, J. A. (1990): Les personifications des provinces dans l'art Romain. Warszawa: Centre d'Archéologie Mediterranéenne de l'Académie Polonaise des Sciences.

Pastor, J. M. (1987): "Las trompetas de guerra celtibéricas”, Celtiberia, 73, pp. 7-19.

Pastor, J. M. (1998): "Ideogramas musicales, onomatopéyicos y animistas en las pinturas figurativas ibéricas y celtibéricas", Kalathos, 17, pp. 1-129.

Pastor, J. M. (2010): “Doble espiral y eses en serie: símbolos gráficos de 'cadencia' en las culturas ibérica y celtibérica”. En Burillo, F. (ed.): Ritos y Mitos. VI Simposio sobre Celtiberos. Daroca: Fund. Segeda, pp. 473-484.

Pernet, L. (2013): "Les représentations d'armes celtiques sur les monuments de victoire aux époques hellénistique et romaine: De la statue de l'Étolie vainqueur à l'arc d'Orange; Origine et mutation d'un stéréotype". En Ménard, H. y Plana-Mallart, R. (eds.): Contacts de cultures, constructions identitaires et stéréotypes dans l'espace méditerranéen Antique. Montpellier: PUM, pp. 21-35.

Petretto, M. A. (1995): "Musica e guerra: note sulla salpinx", Sandalion, 18, pp. 35-53.

Piggott, S. (1959): "The Carnyx in Early Iron Age Britain”, Antiquaries Journal, 39, pp. 19-32.

Polito, E. (1998): Fulgentibus armis. Introduzione allo studio dei fregi d'armi antichi. Roma: L'Erma di Bretschneider.

Poux, M. (2009): "Banquete y consumo del vino en la Galia a finales de la Edad del Hierro". En SAnZ, C. y Romero, F. (eds.): El vino y el banquete en la Europa prerromana. Valladolid: Univ. de Valladolid, pp. 93112.

Raepsaet-Charlier, M. T. (1993): Diis deabusque sacrum. Formulaire votif et datation dans les Trois Gaules et les Deux Germanies. Paris: De Boccard.

Raftery, B. (1991): "I celti pre-cristiani delle isole". En Moscati, S. (ed.): I celti. La prima Europa. Milano: Bompiani, pp. 555-572.

Raftery, B. (2001): "La Edad del Hierro en Irlanda y la fachada atlántica”. En Almagro, M.; Mariné, M. y Álvarez, J. (eds.): Celtas y vettones. Ávila: Diput. Ávila, pp. 63-71.

RIG = Lejeune, 1985 .

Ritchie, W. F. y Ritchie, J. N. G. (1985): Celtic Warriors. Risborough: Shire.

$\mathrm{RRC}=$ Crawford, 1974.
Romero, F.; Sanz, C.; Górriz, C. y De Pablo, R. (2013): "Los sonajeros vacceos", Boletín del Seminario de Arte y Arqueología, LXxIx, pp. 81-129.

Roncador, R. (2014): "Celti e Reti tra v e i sec. a. C.: contesto culturale e progetto di ricerca 'Karnyx di Sanzeno'”. En Roncador, R. y Nico, F. (eds.): Antichi popoli delle Alpi. Sviluppi culturali durante l'Età del Ferro nei territori alpini centro-orientali. Sanzeno: Provincia autonoma di Trento, pp. 157-181.

Ross, A. (1967): Pagan Celtic Britain. London: Routledge-Kegan Paul.

Rudd, C. (2010): Ancient British Coins. Norwich: Page Bros.

Rybová, A. y Drda, P. (1994): Hradišsé by Stradonice: Rebirth of a Celtic Oppidum. Praha: Institute of Archaeology.

RYM = Burillo, 2010.

Schröder, S. (1999): Geschichte und Theorie der Gattung Paian. Stuttgart y Leipzig: Teubner.

Sergent, B. (1991): "Ethnozoonymes indo-européens", Dialogues d'Histoire Ancienne, 17, pp. 9-55.

Serghidou, A. (2001): "Athena Salpinx and the Ethics of Music”. En Deacy, S. y Villing, A. (eds.): Athena in the Classical World. Leiden: Brill, pp. 57-74.

SopeÑA, G. (1995): Etica y ritual. Aproximación al estudio de la religiosidad de los pueblos celtibéricos. Zaragoza: IFC.

SopeÑA, G. (2010): "La ideología de la muerte en el ámbito celtibérico. Evidencias rituales y nuevas perspectivas". En Burillo, F. (ed.): Ritos y Mitos. VI Simposio sobre Celtiberos. Daroca: Fund. Segeda, pp. 245-271.

Sopeña, G. (2012): "Motivos animales en las trompetas de guerra célticas". En Ruiz, F. y García Huerta,

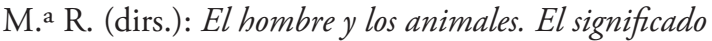
simbólico de los animales desde la Protohistoria hasta fines de la Edad Media. Madrid: Síntesis, pp. 91-99.

Sopeña, G. y Ramón, V. (2002): "Claudio Eliano y el funeral descarnatorio en Celtiberia. Reflexiones críticas a propósito de Sobre la naturaleza de los animales x, 22", Palaeohispánica, 2, pp. 227-269.

Sopeña, G. y Ramón, V. (2019): "Sobre perros y buitres. Apuntes preliminares acerca de Juan Estobeo, Antología vi. 55, 11", Bandue, 11, pp. 241-253.

Sterckx, C. (1998): Sangliers Père \& Fils. Dieux, rites et mythes celtes $d u$ porc et $d u$ sanglier. Bruxelles: MSBÉC.

Stern, J. (2008): "Paradoxographus Vaticanus". En Heilen, S. (ed.): Pursuit of Wissenschaft: Festschrift für William M. Calder III zum 75. Geburtstag. Spudasmata, Bd. 119. Hildesheim-Zurich-New York: Georg Olms, pp. 437-466. 
Swan, D. (2018): "The carnyx on Celtic and Roman Republican Coinage”, Antiquaries Journal, 98, pp. 81-94.

Szabó, M. (1991): "I celti e il loro spostamenti nel III secolo a. C.”. En Moscati, S. (ed.): I celti. La prima Europa. Milano: Bompiani, pp. 303-319.

sZM II = Hickmann et al., 2000.

SZM III = Hickmann et al., 2002.

Van Andringa, W. (2002): La religion en Gaule romaine. Paris: Errance.

VendRies, C. (1999): "La trompe, le gaulois et le sanglier”, Revue des Etudes Anciennes, 101, pp. 367-391.

Veres, J. (2009): "The depiction of a carnyx-player from the Carpathian Basin”, Archäologisches Korrespondenzblatt, 39, pp. 231-249.

Villar, F. y Prósper, B. M. ${ }^{a}$ (2005): Vascos, celtas e indoeuropeos. Genes y lenguas. Salamanca: Univ. de Salamanca.

Vincent, A. (2020): "Les cornua dans le monde romain: usages et perceptions". En Vendries, Ch. (ed.):
Cornua de Pompéi: Trompettes romaines de la gladiature. Rennes: PUR, pp. 13-30.

West, M. L. (1994): Ancient Greek Music. Oxford: Clarendon Press.

Woyteк, B. (2015): "Der Fremde im Münzbild. Zur Herausbildung ikonographischer Konventionen der Darstellung von Barbaren in der römischen Münzprägung". En Pülz, A. y Trinkl, E. (eds.): Das Eigene und das Fremde. Akten der 4. Tagung des Zentrums Archäologie und Altertumswissenschaften an der Österreichischen Akademie der Wissenschaften. Wien: Austrian Academy of Sciences Press, pp. 105-122.

Xanthoulis, N. (2006): “The Salpinx in Greek Antiquity”, International Trumpet Guild Journal, 41, pp. $39-45$.

Zanker, P. (1988): The Power of Images in the Age of Augustus. Ann Arbor: UMP. 